Supporting Information for

\title{
Regiospecific Synthesis of Benzoxepines through Pd-Catalyzed Carbene Migratory Insertion and $\mathrm{C}-\mathrm{C}$ bond Cleavage
}

\author{
Yang Xie, Ping Zhang, and Lei Zhou* \\ School of Chemistry and Chemical Engineering, Sun Yat-Sen University, 135 Xingang West Road, \\ Guangzhou, 510275, China.
}

CONTENTS

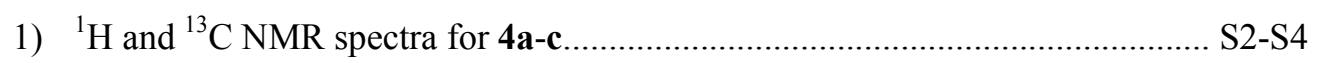

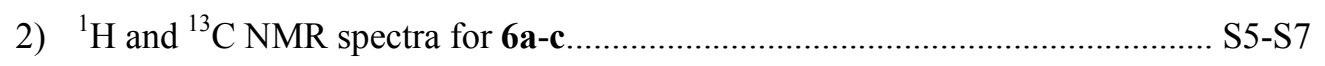

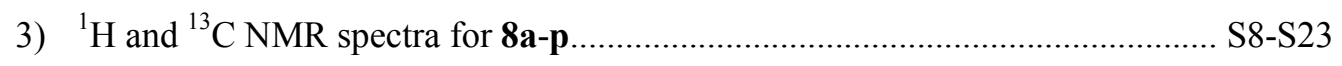




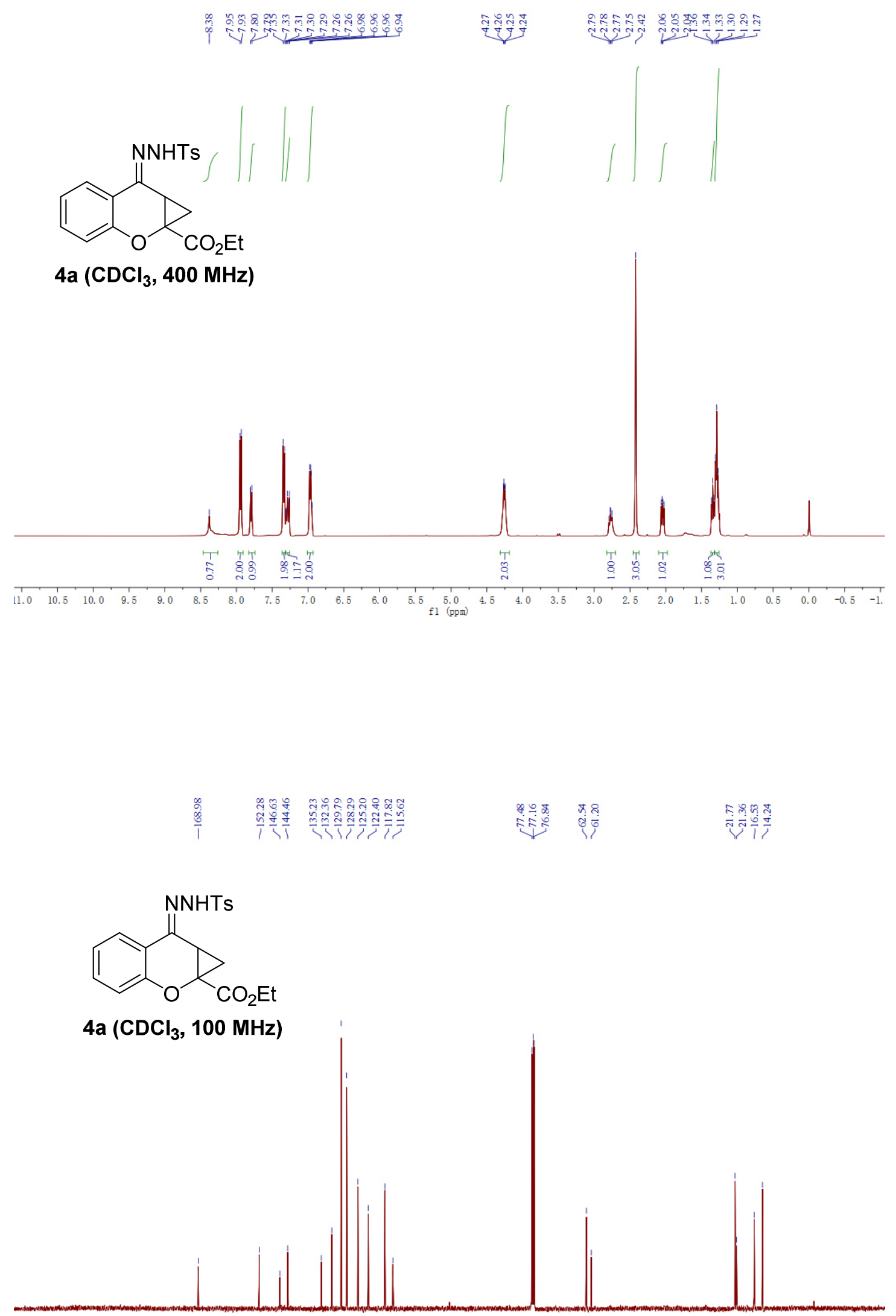

(a (CDCl, 100 

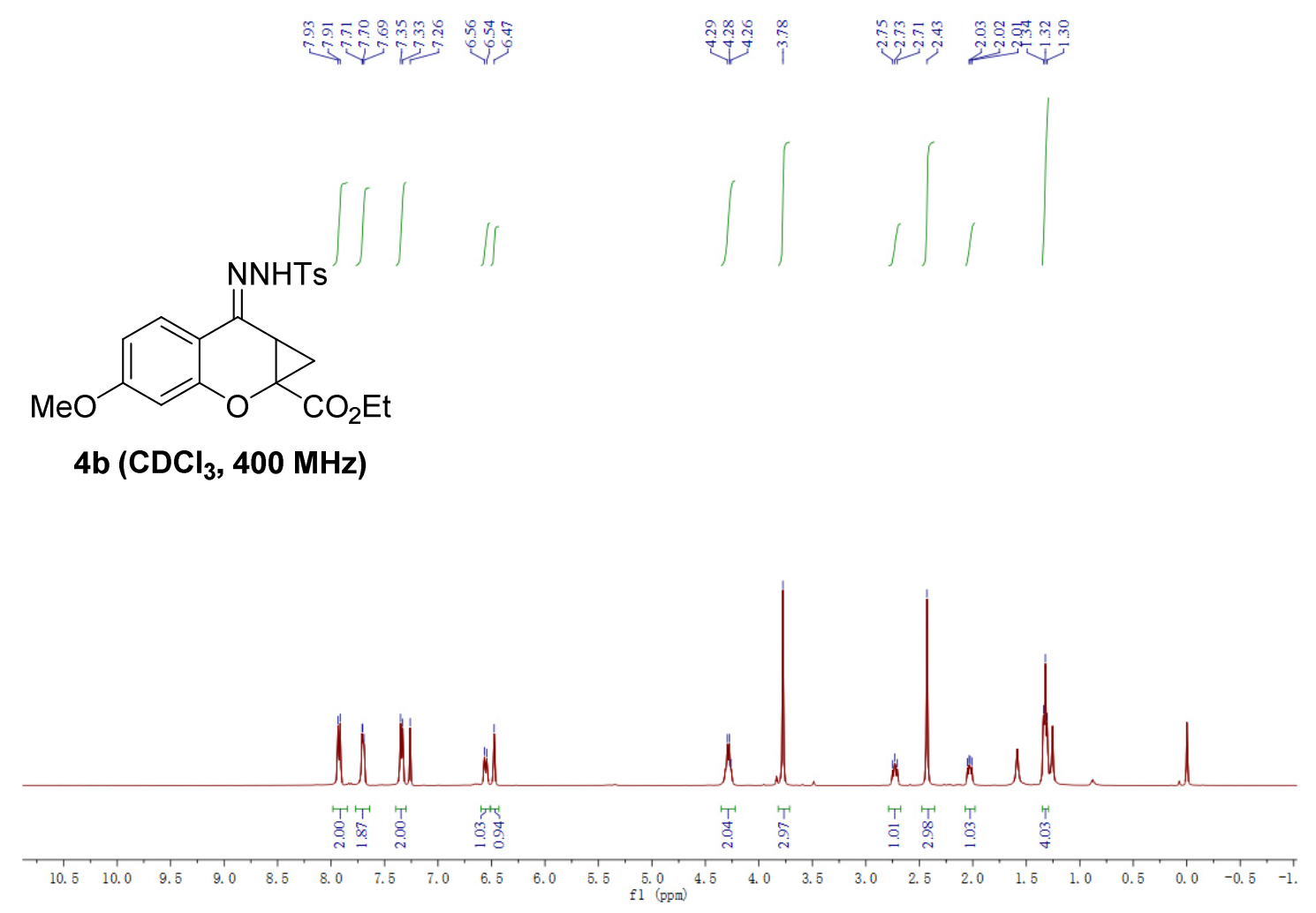

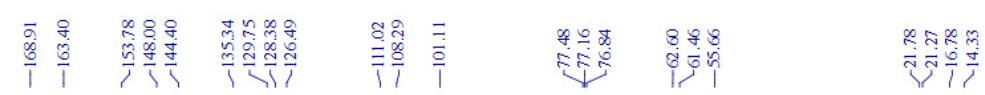
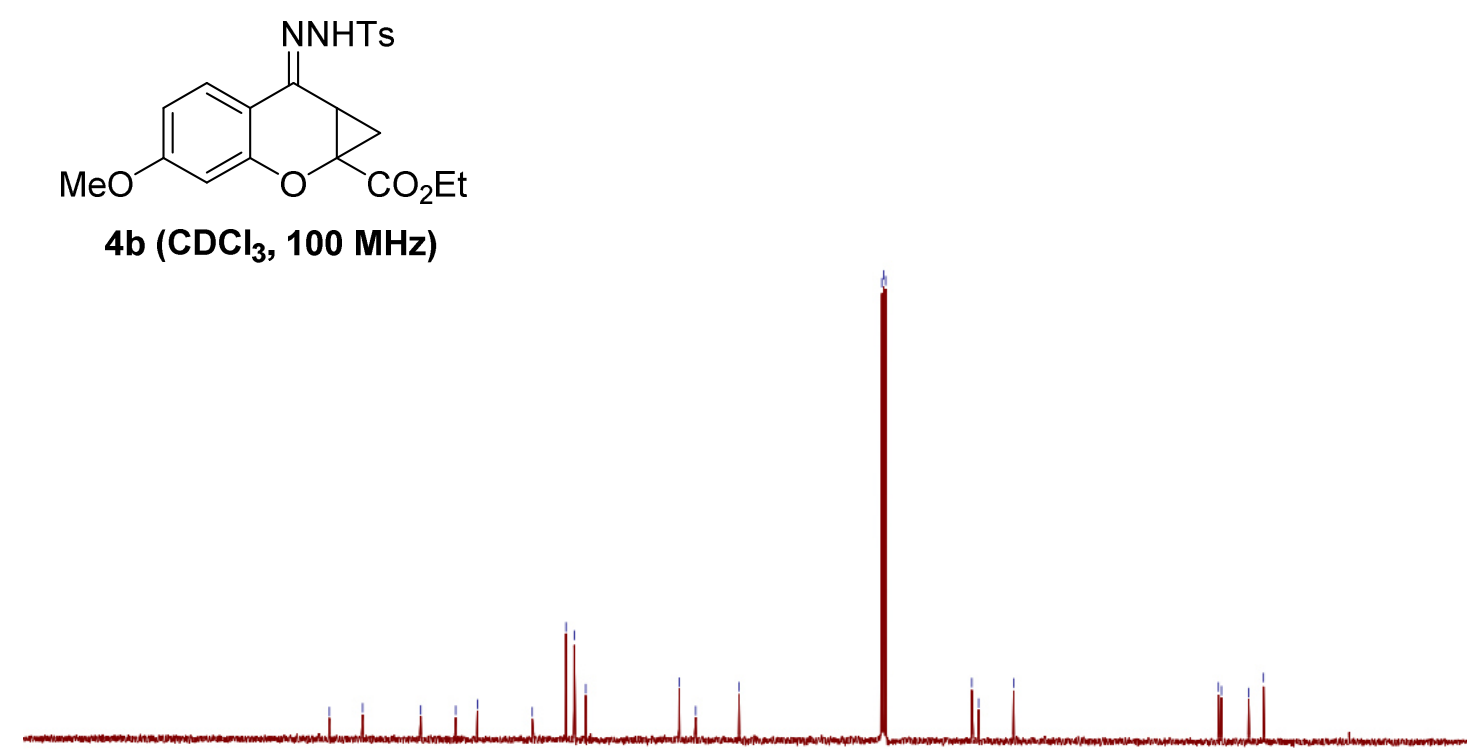

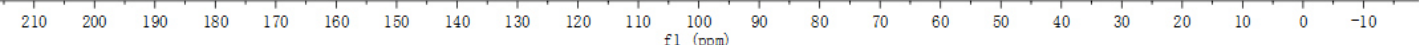



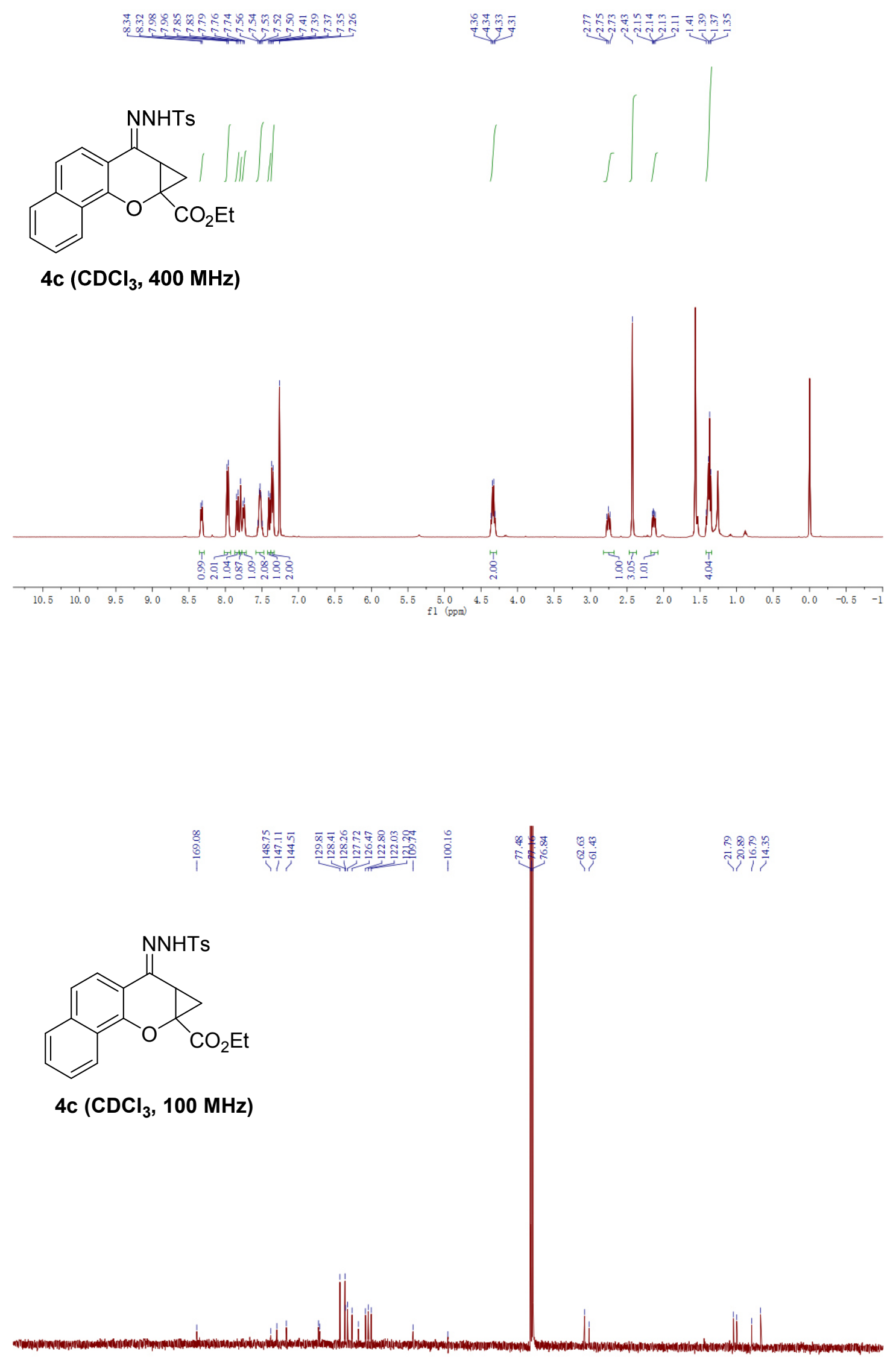

$\begin{array}{llllllllllll}110 & 200 & 190 & 180 & 170 & 160 & 150 & 140 & 130 & 120 & 110 & 100 \\ \mathrm{f} 1(\mathrm{ppm}) & \end{array}$ 

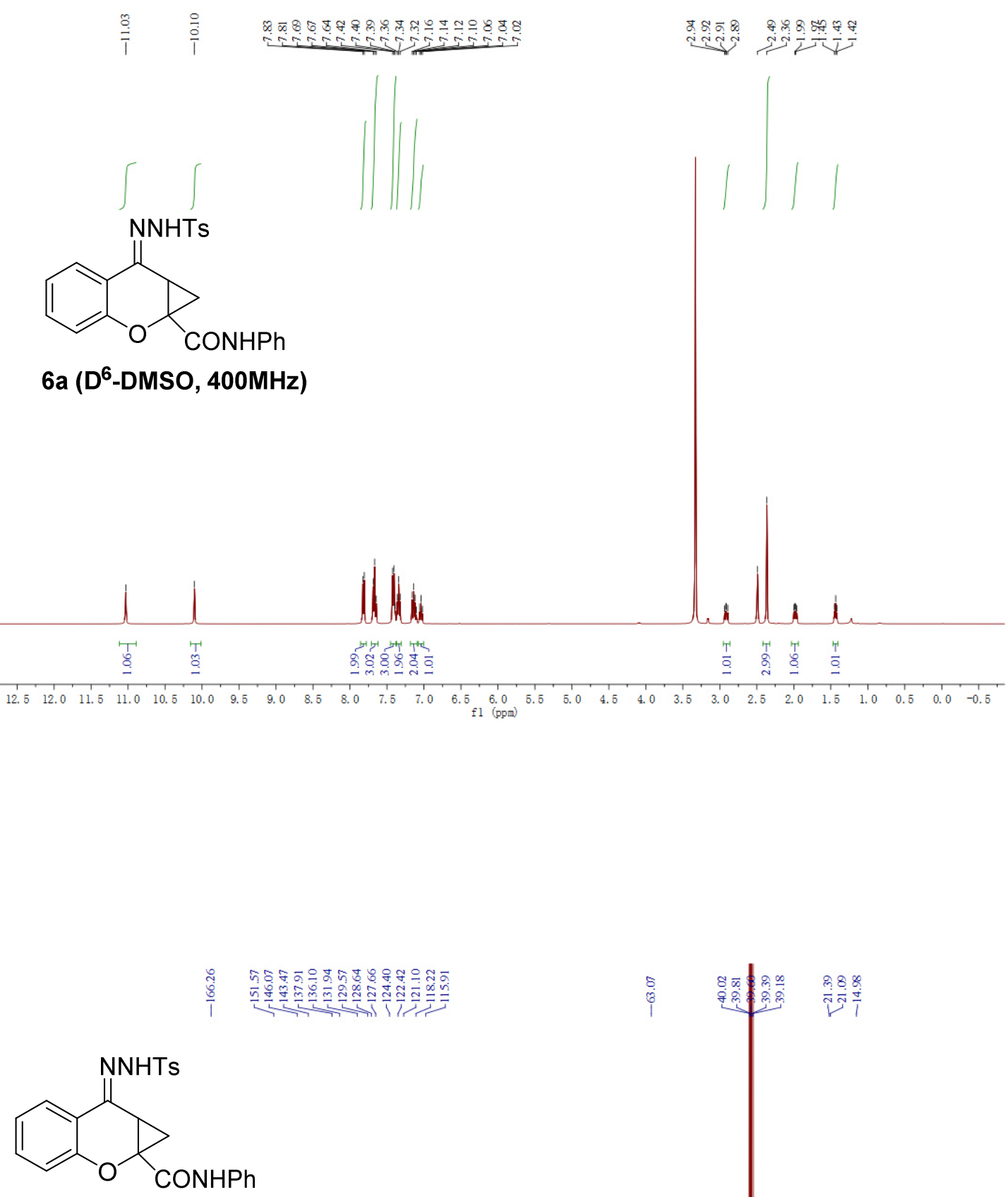

6a (D'-DMSO, 100MHz)

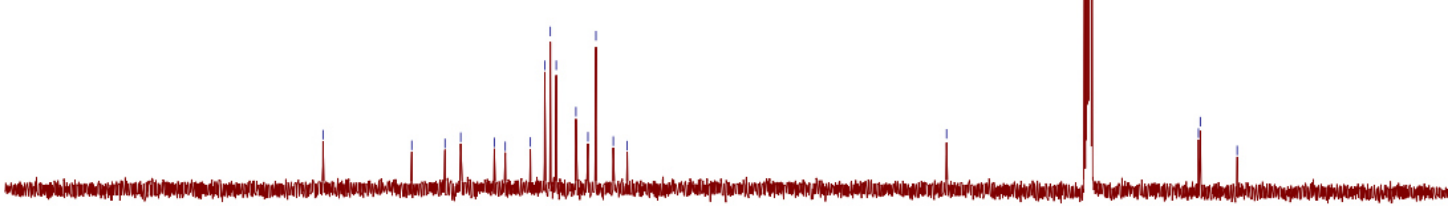

$\begin{array}{lllllllllllllllllllllll}210 & 200 & 190 & 180 & 170 & 160 & 150 & 140 & 130 & 120 & 110 & 100 & 90 & 80 & 70 & 60 & 50 & 40 & 30 & 20 & 10 & 0 & -10\end{array}$ 

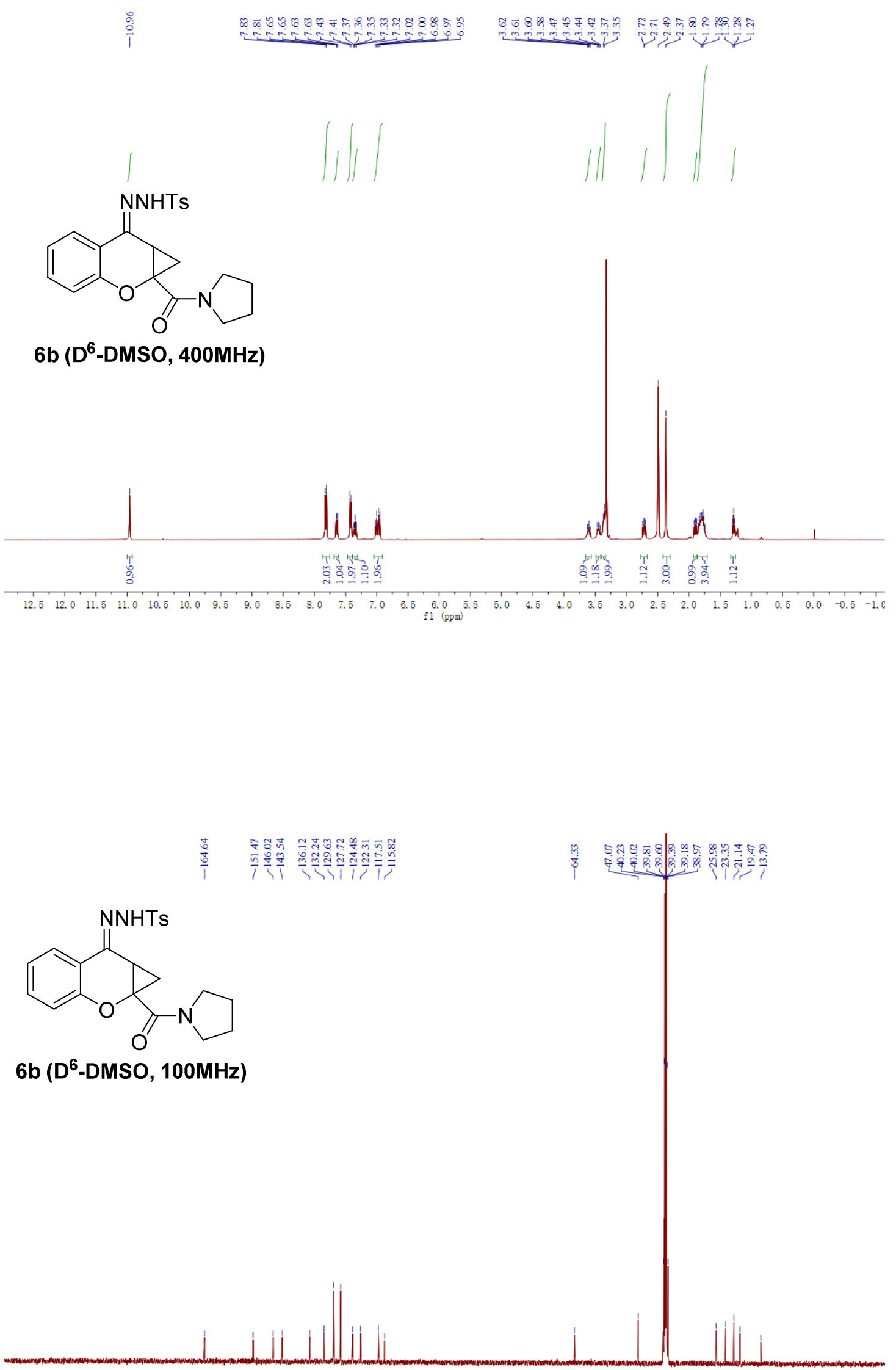

$\begin{array}{llllllllllll}210 & 200 & 190 & 180 & 170 & 160 & 150 & 140 & 130 & 120 & 110 & 100 \\ \mathrm{fl}(\mathrm{ppm}) & 9\end{array}$ 


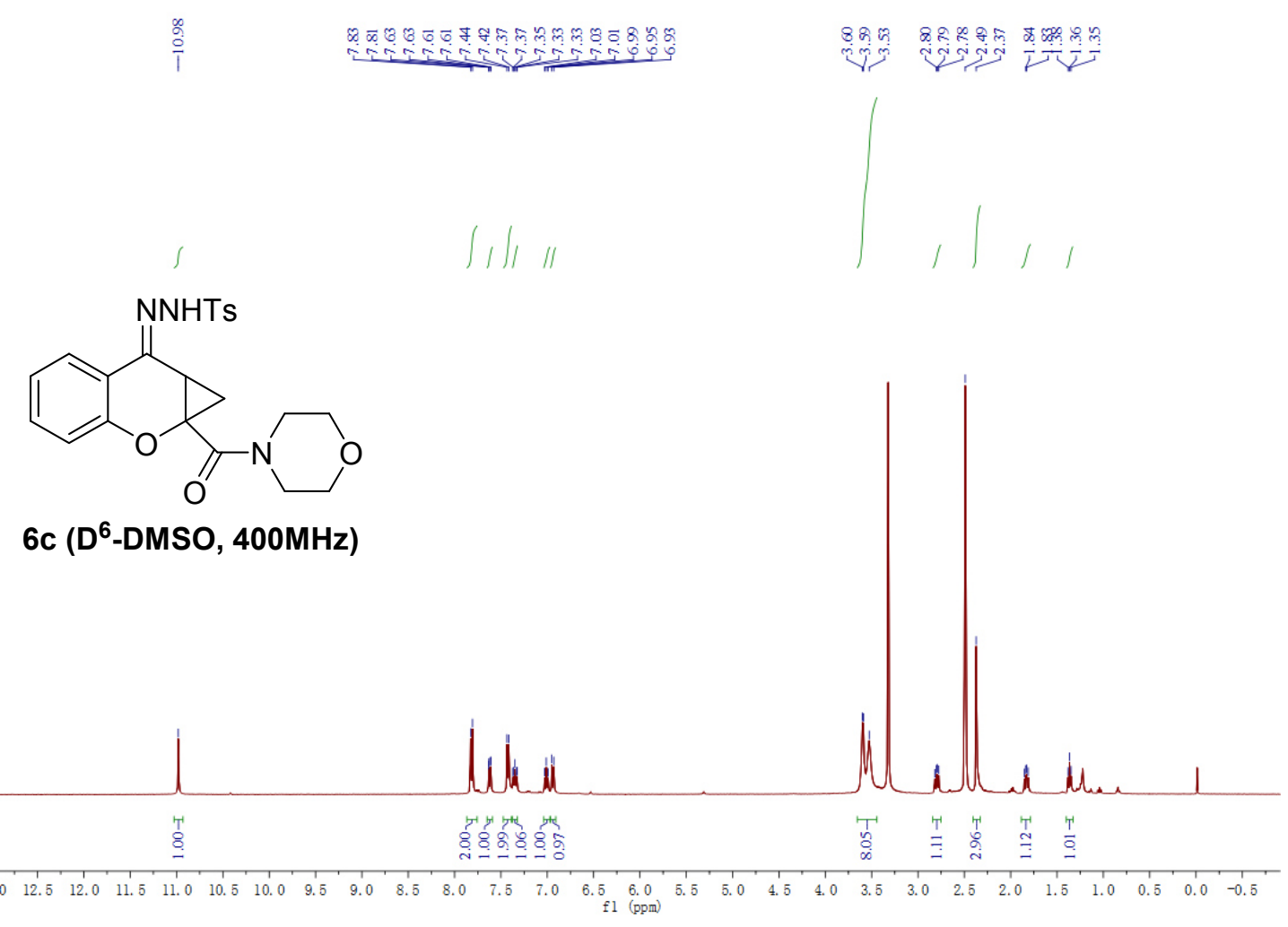

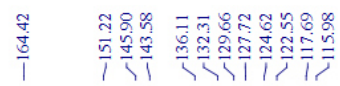

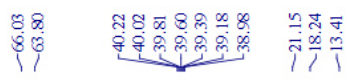

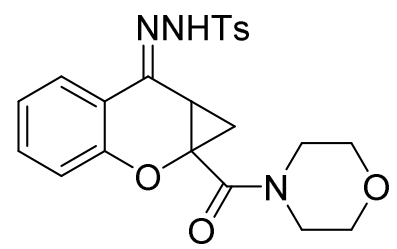

6c (D6-DMSO, 100MHz)

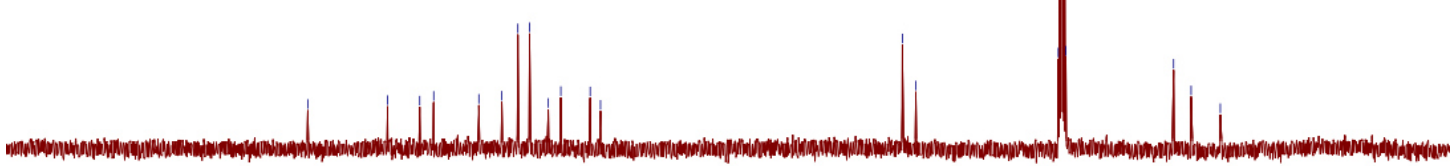

\begin{tabular}{llllllllllll}
210 & 200 & 190 & 180 & 170 & 160 & 150 & 140 & 130 & 120 & 110 & $\begin{array}{l}100 \\
\mathrm{f} 1(\mathrm{ppm})\end{array}$ \\
\hline
\end{tabular} 


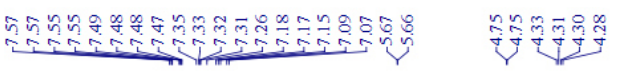

$\sqrt[4]{7}$
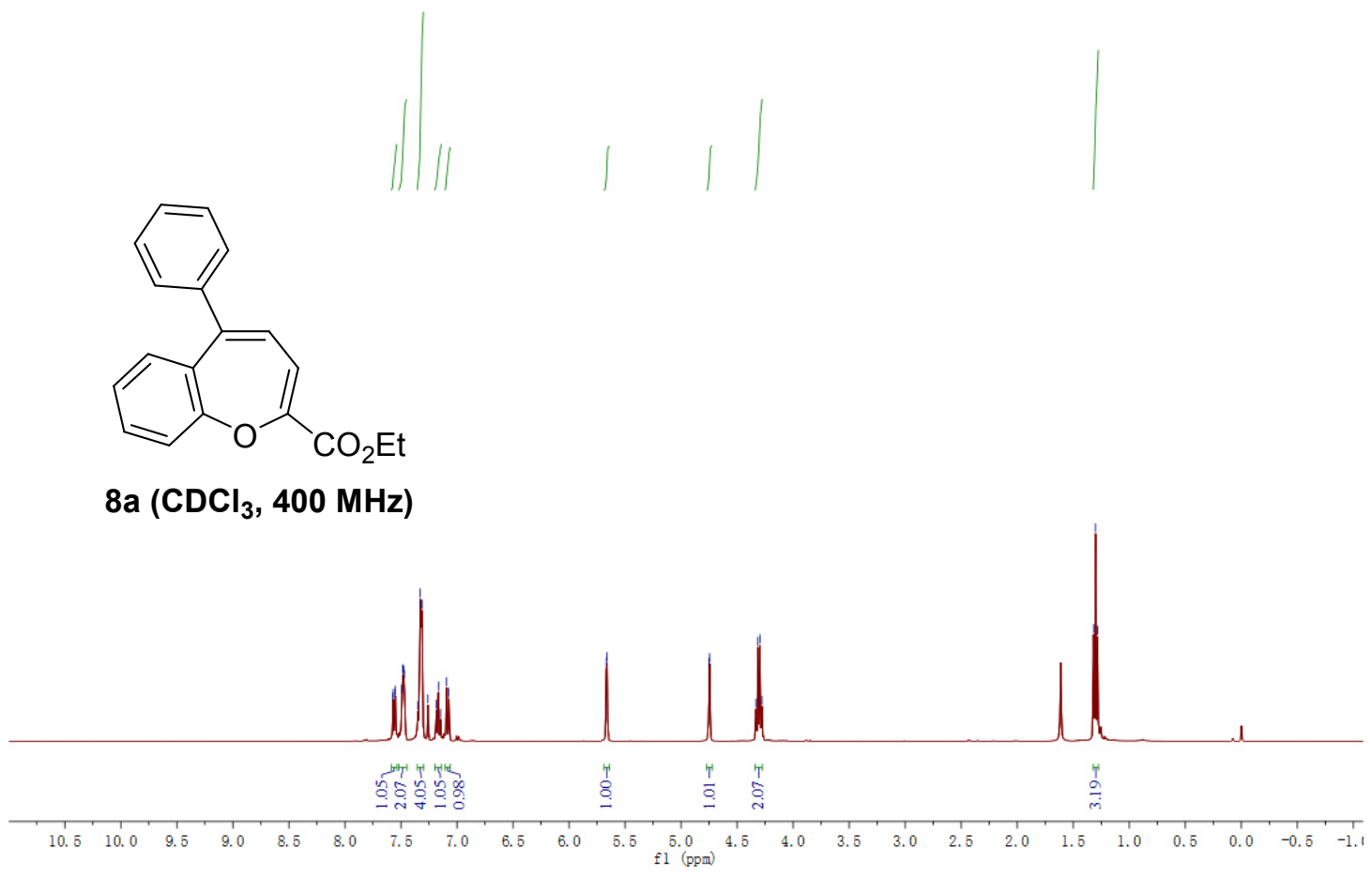

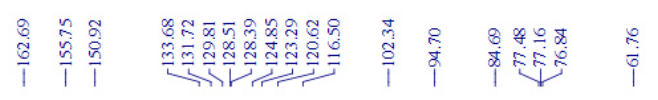

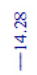
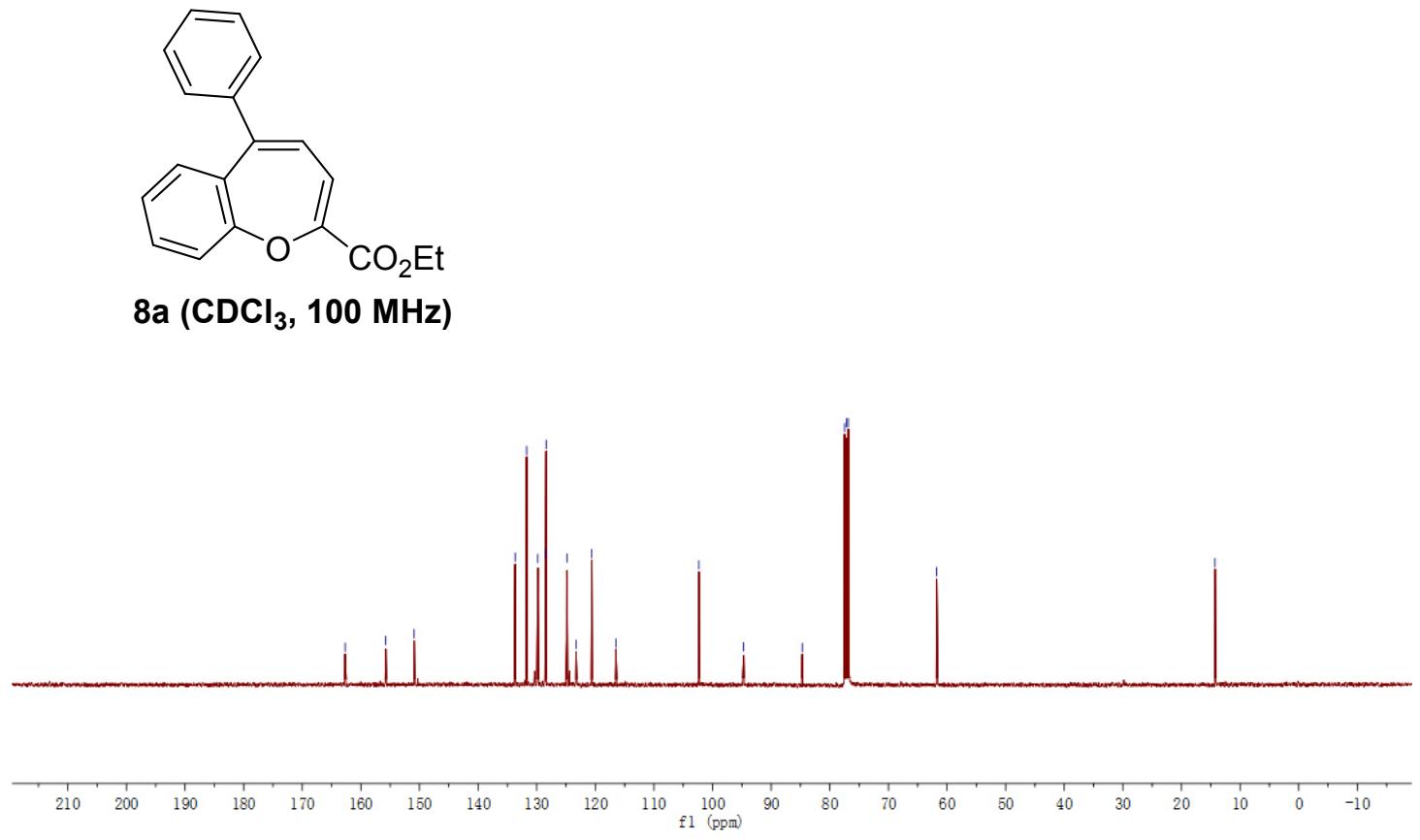

S8 

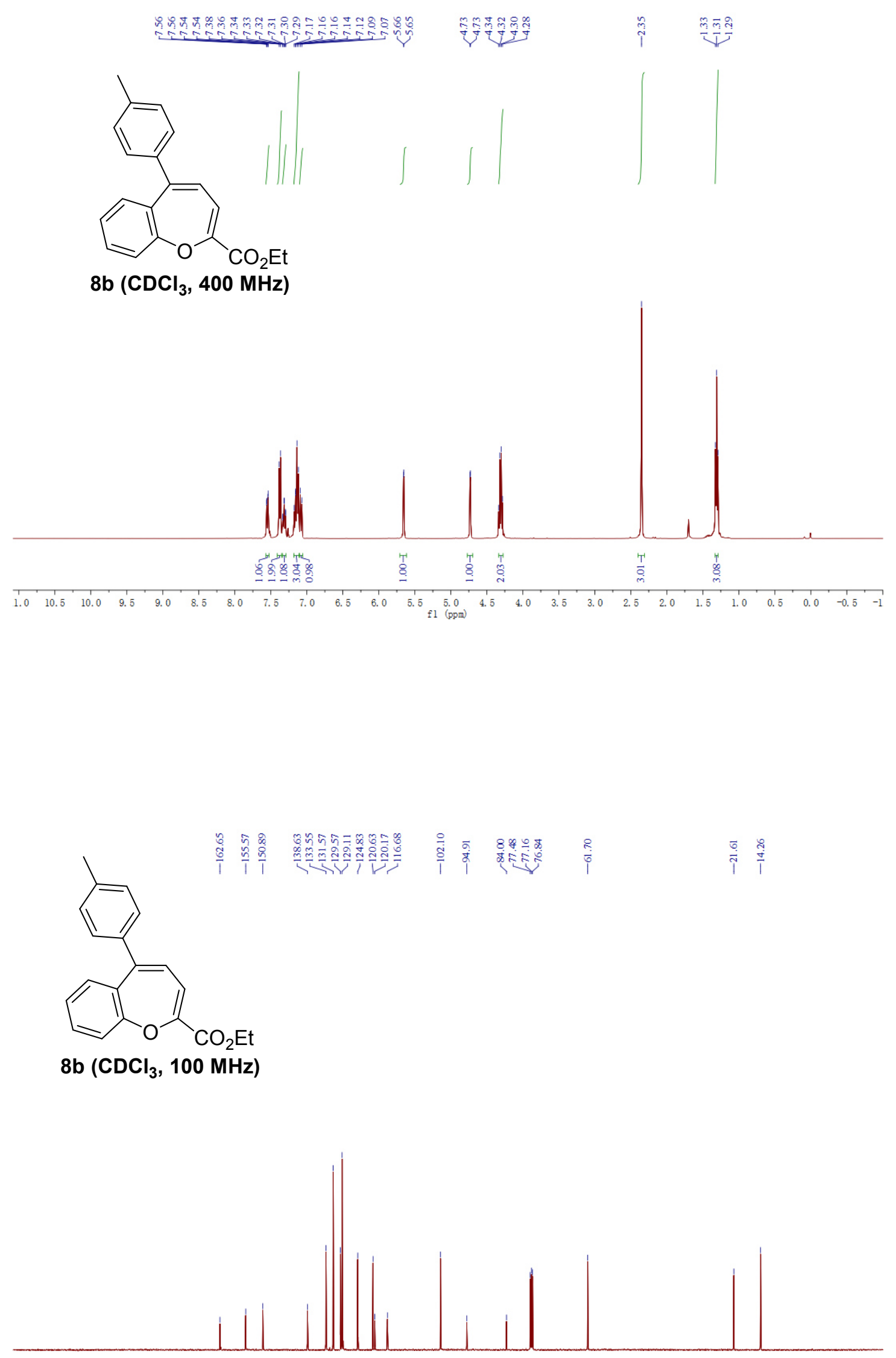

$\begin{array}{llllllllllll}210 & 200 & 190 & 180 & 170 & 160 & 150 & 140 & 130 & 120 & 110 & 100 \\ \mathrm{f} 1(\mathrm{ppm}) & 90\end{array}$ 


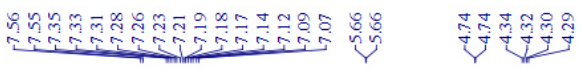
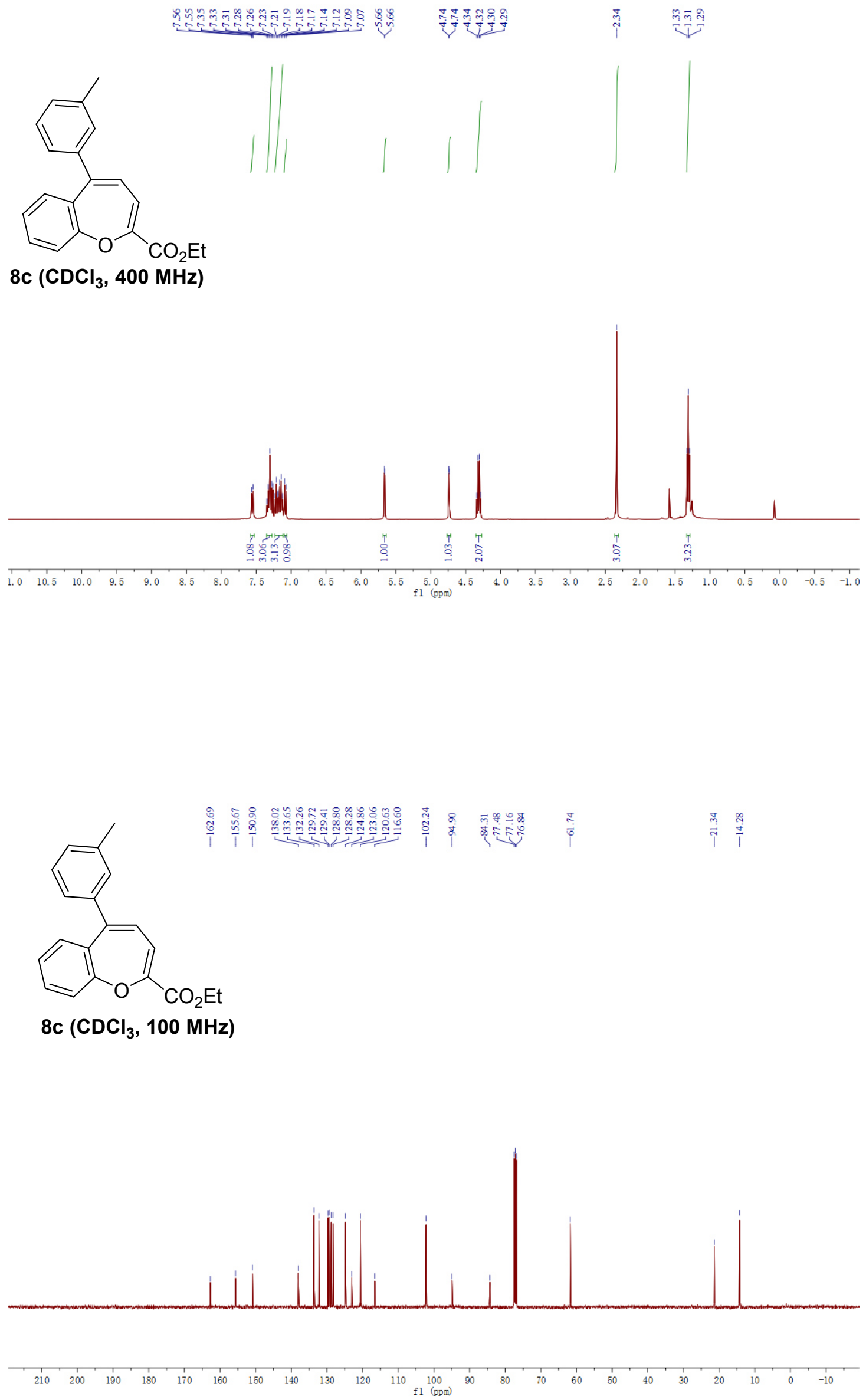

S10 


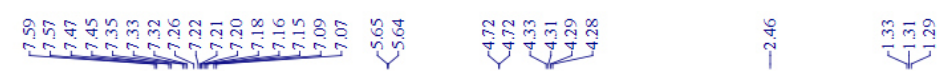

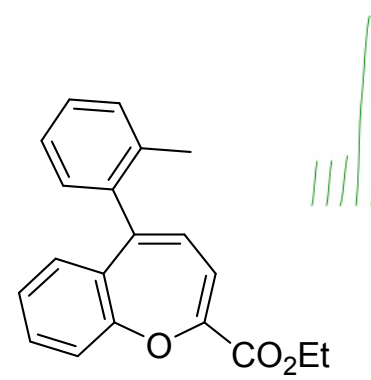

8d $\left(\mathrm{CDCl}_{3}, 400 \mathrm{MHz}\right)$
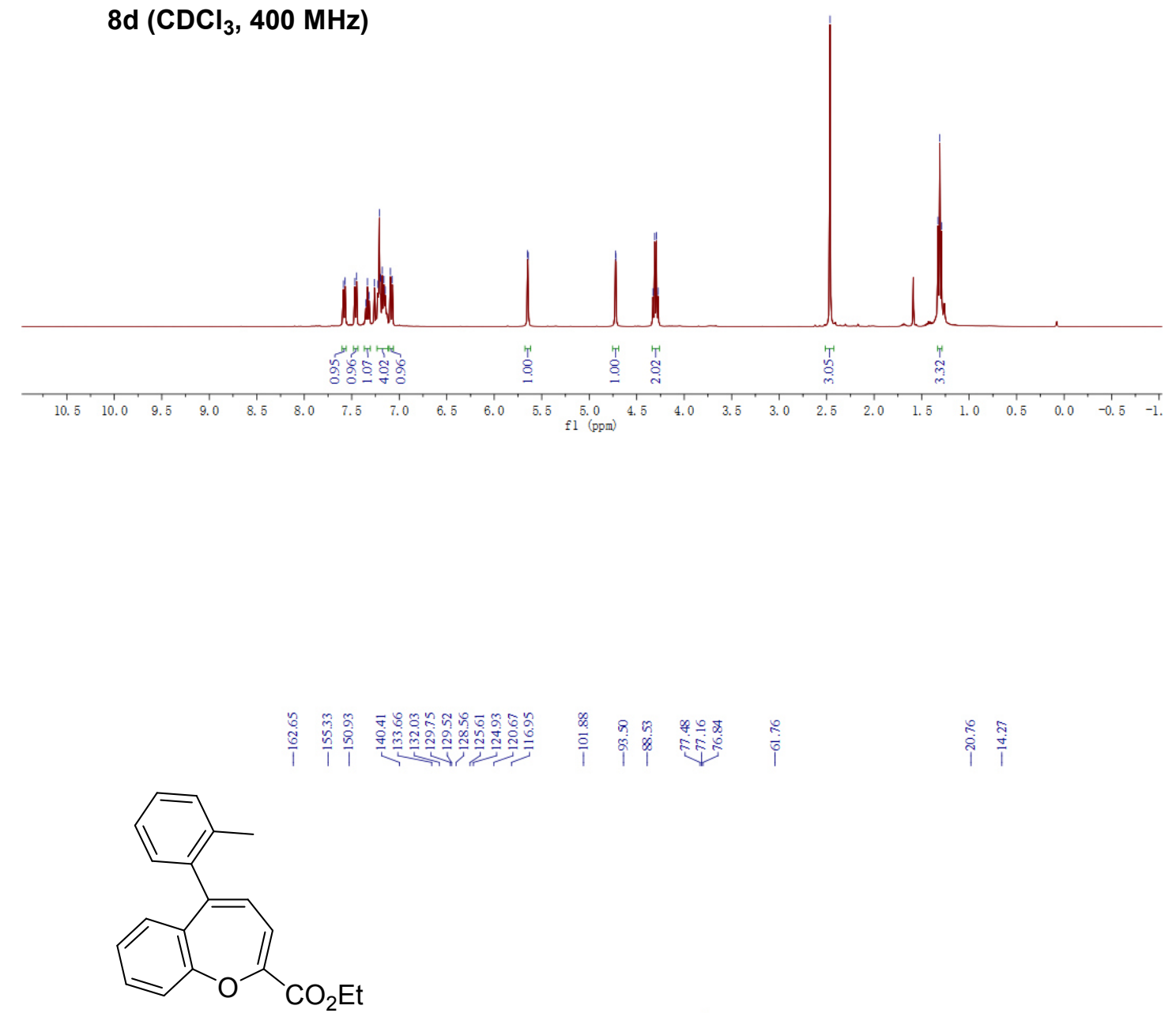

8d (CDCl3, $100 \mathrm{MHz})$

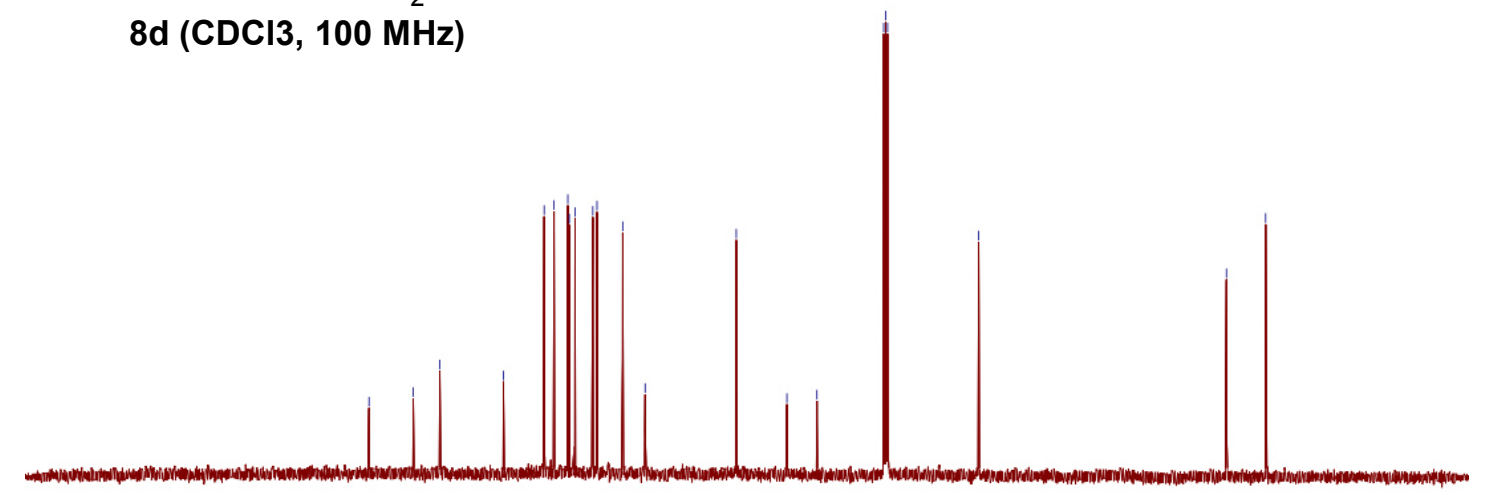

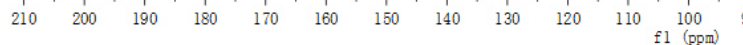




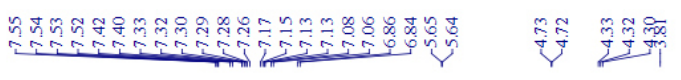

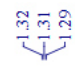
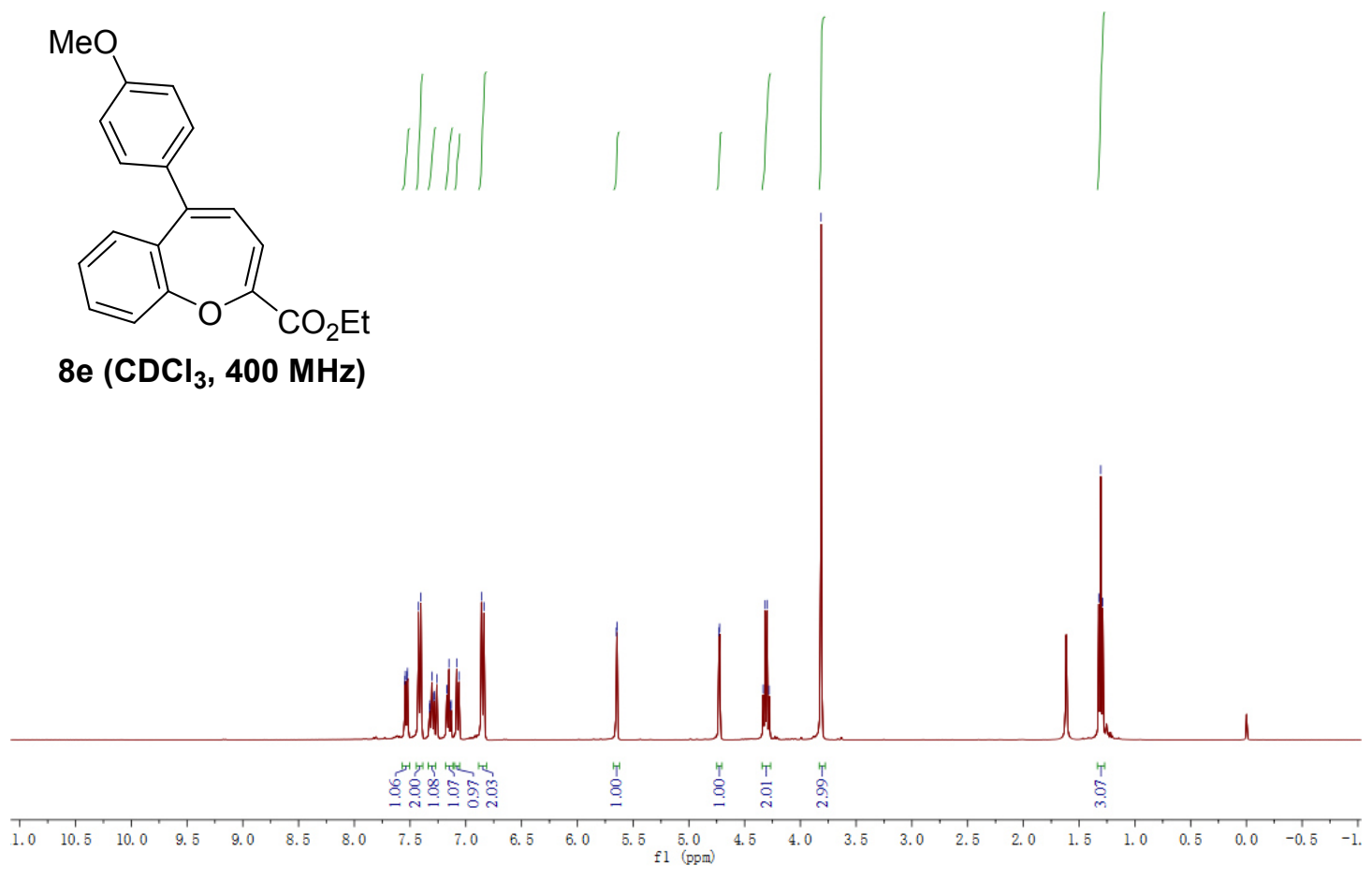

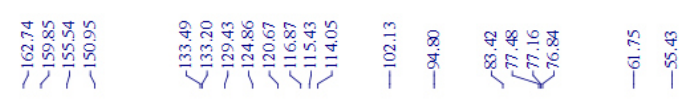

$\frac{8}{1}$
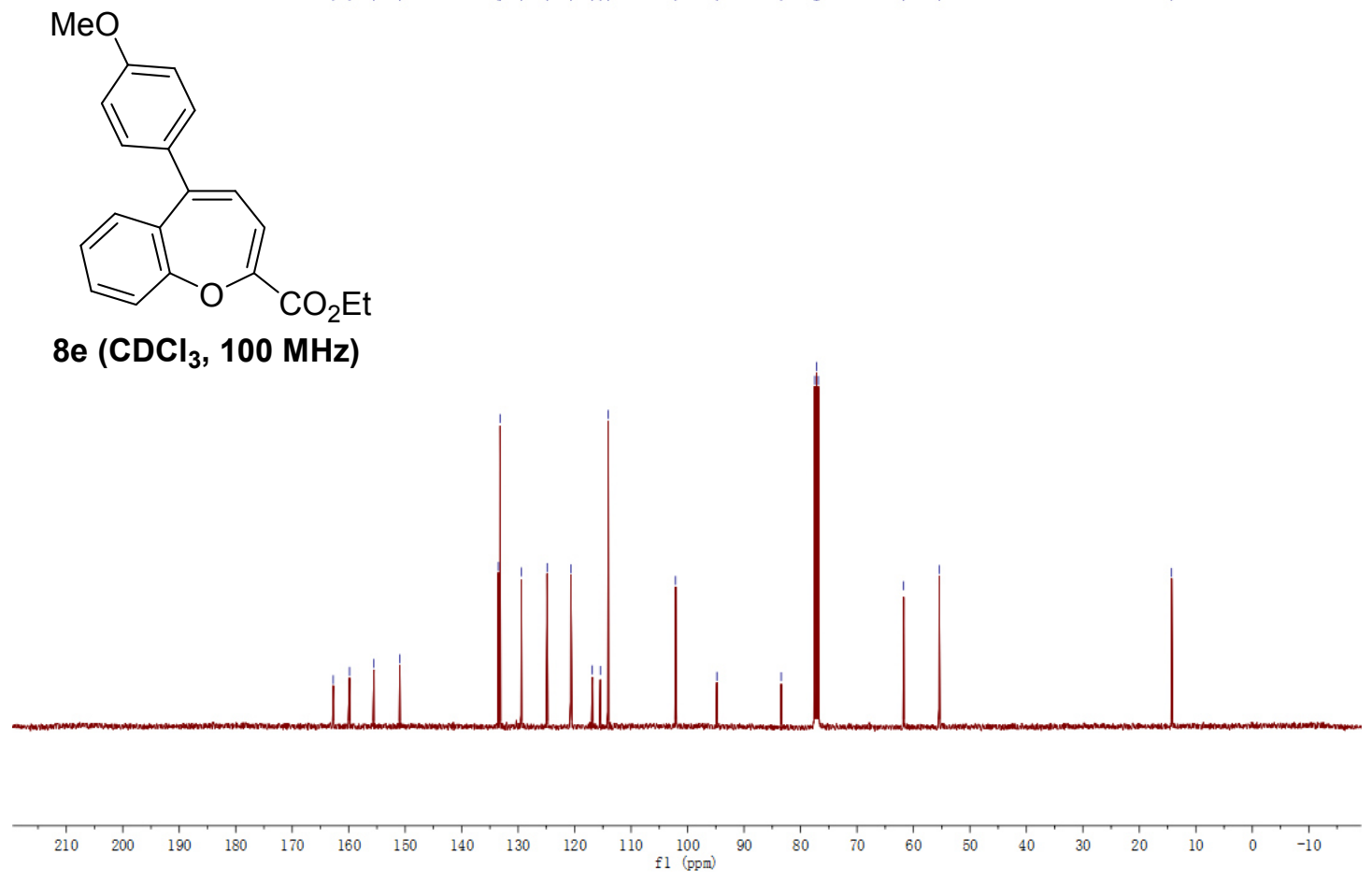

S12 


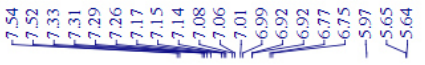

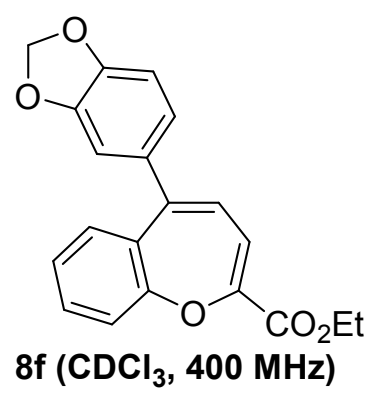

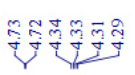

远等

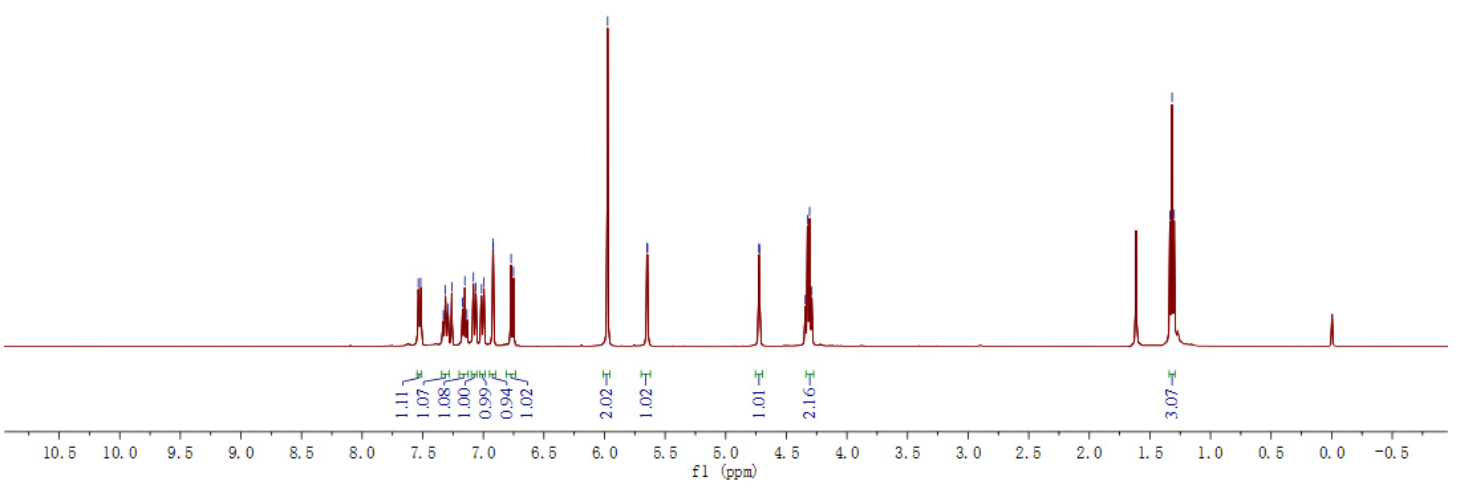

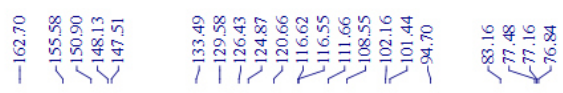

$\frac{2}{\bar{\varphi}}$
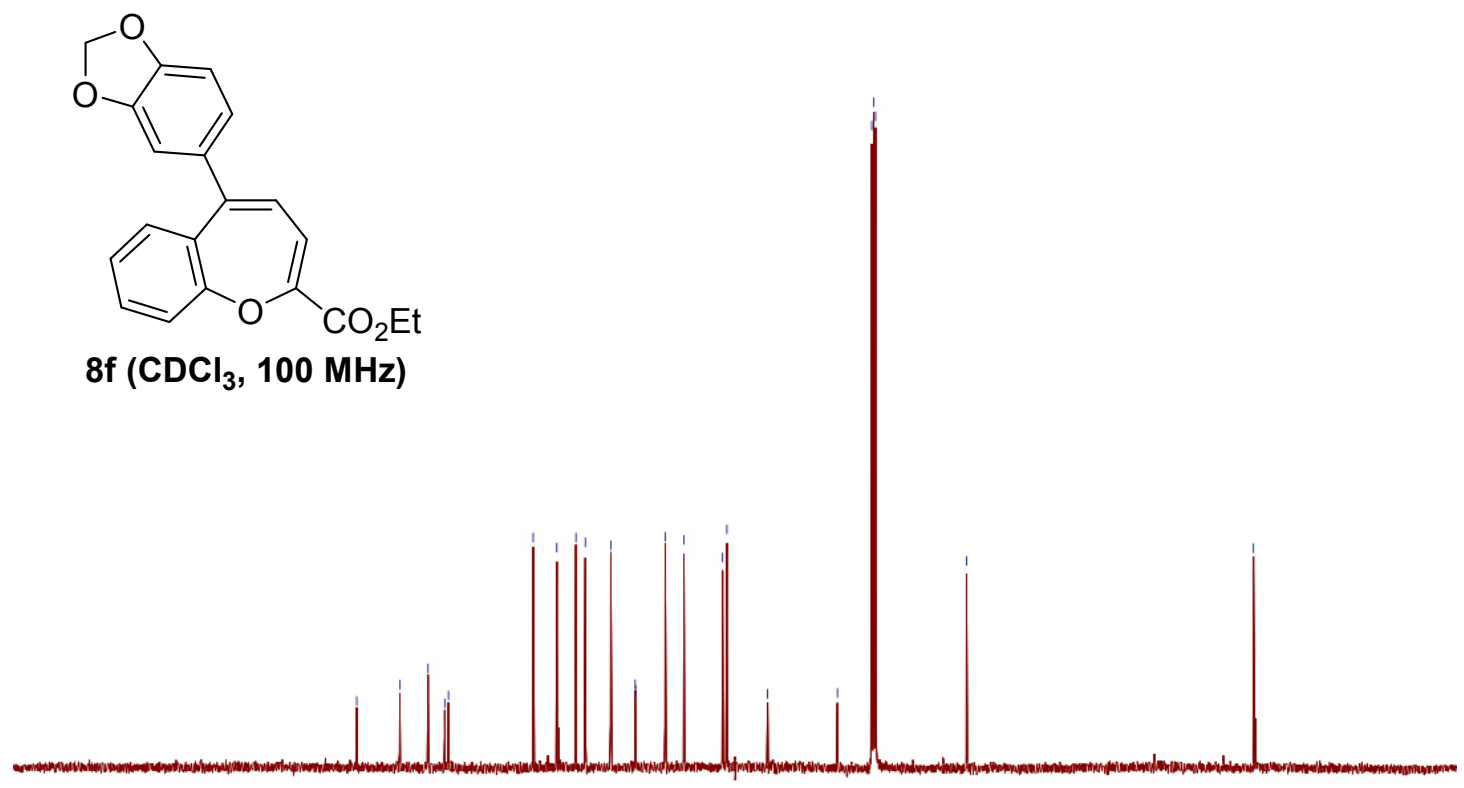

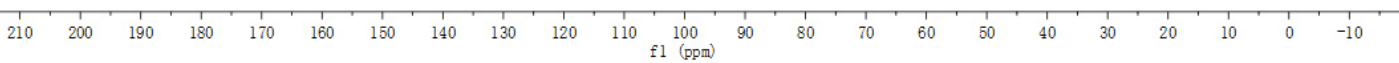

S13 


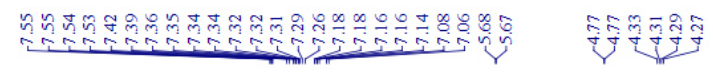
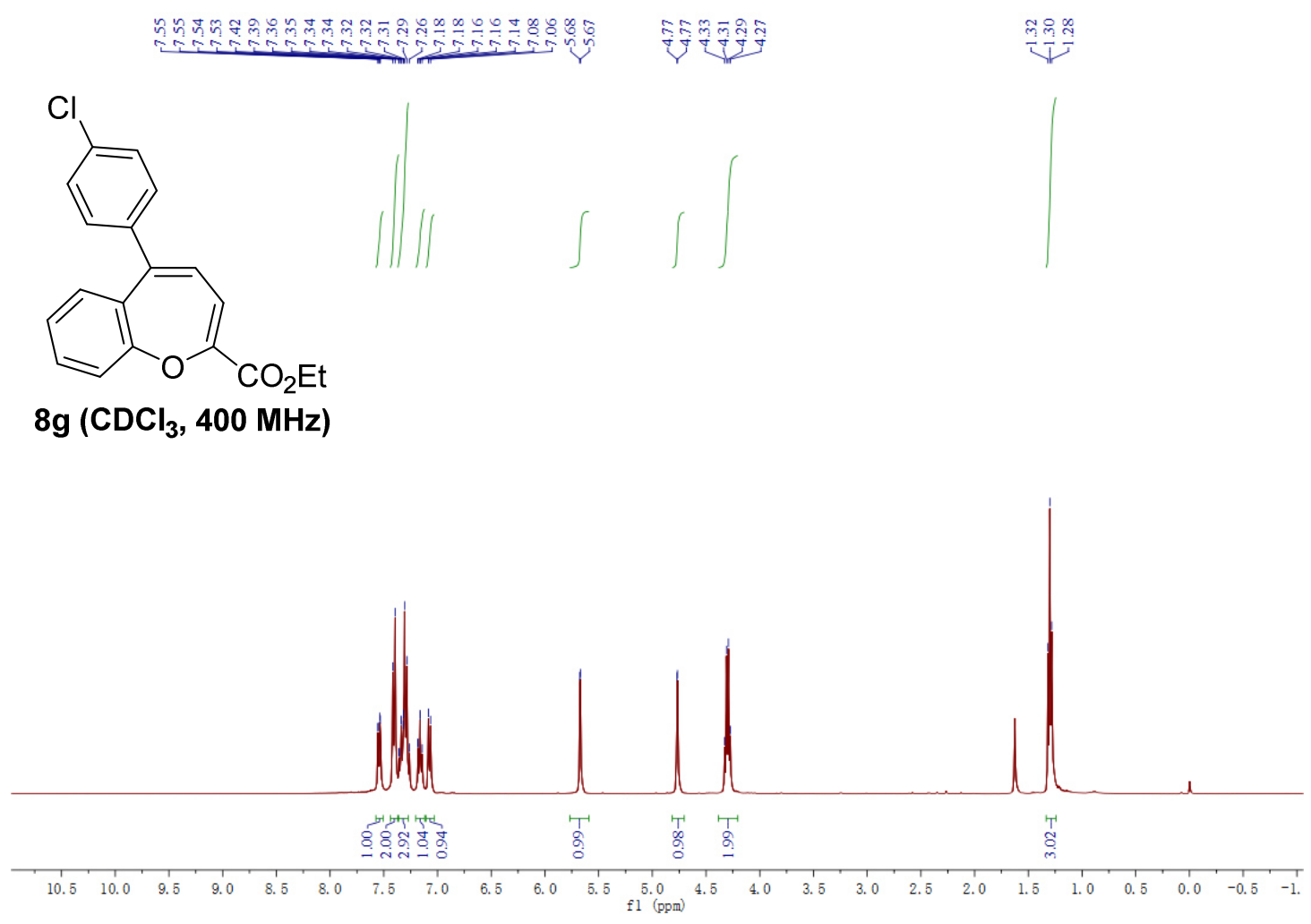

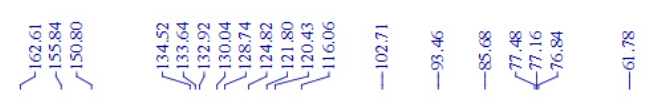

$\underset{\substack{1 \\ \frac{1}{1}}}{2}$
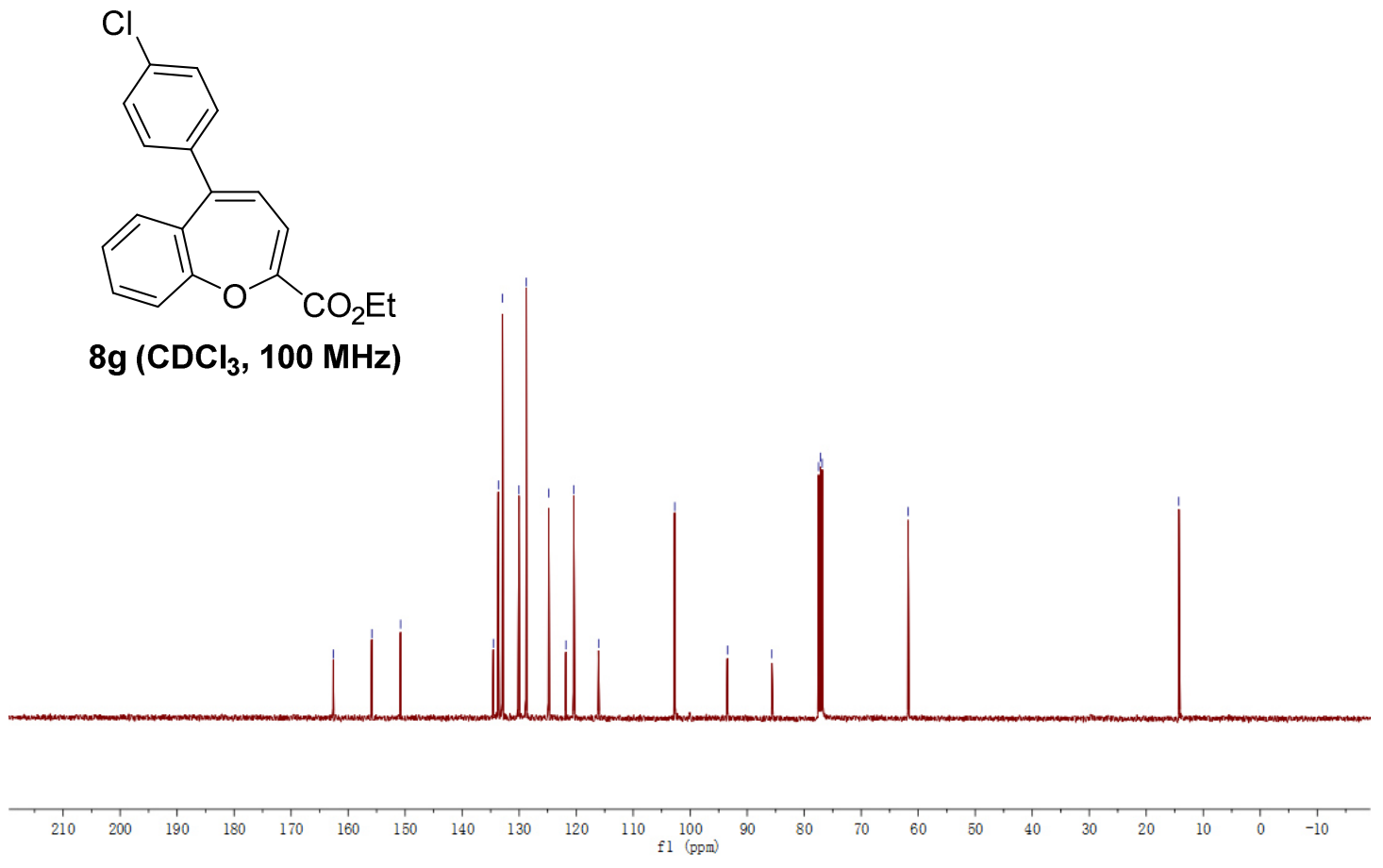

S14 


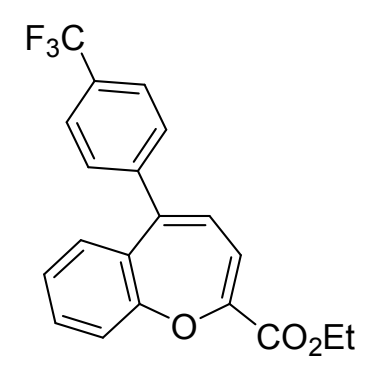

8h $\left(\mathrm{CDCl}_{3}, 400 \mathrm{MHz}\right)$

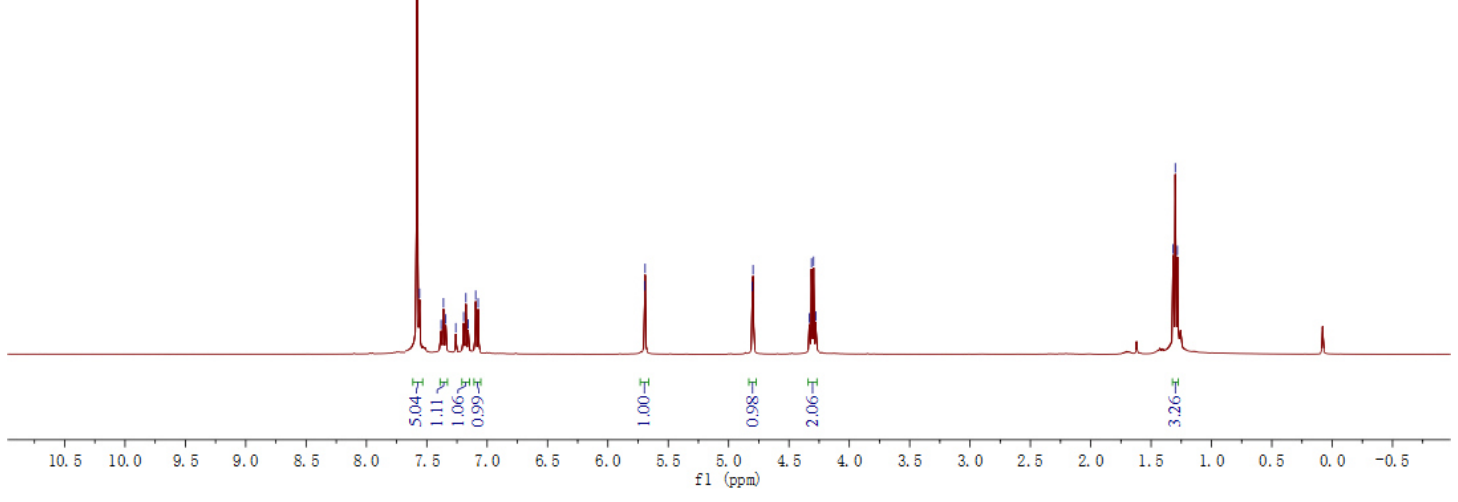

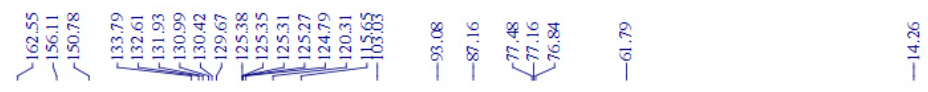

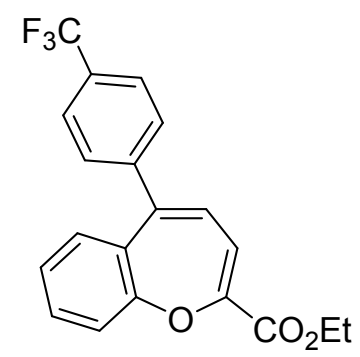

8h $\left(\mathrm{CDCl}_{3}, 100 \mathrm{MHz}\right)$

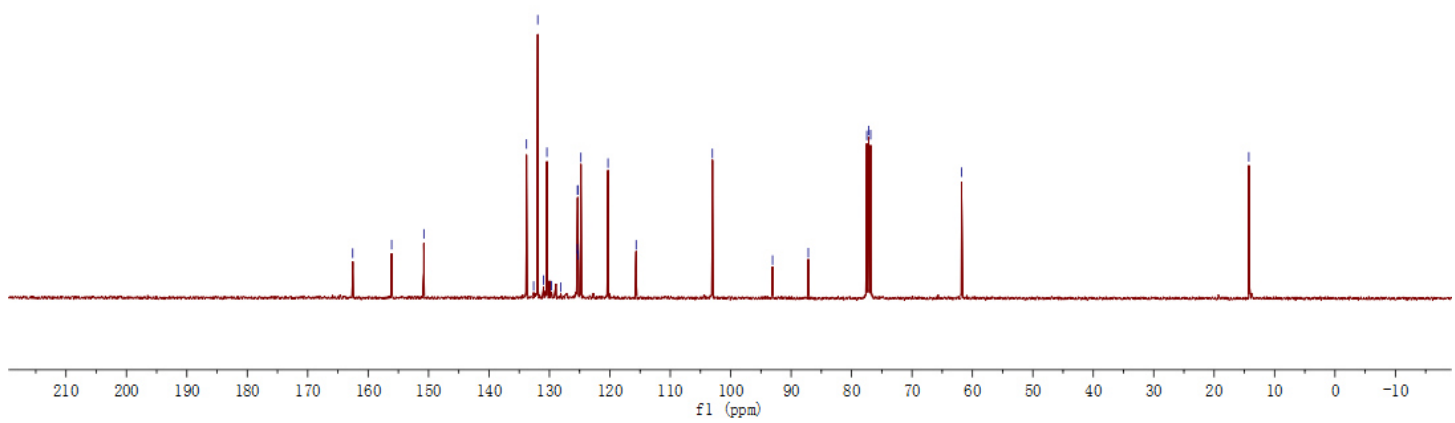




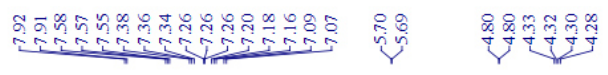

$\underset{\text { i }}{\text { i }}$

$\frac{8}{4} \frac{7}{4}$
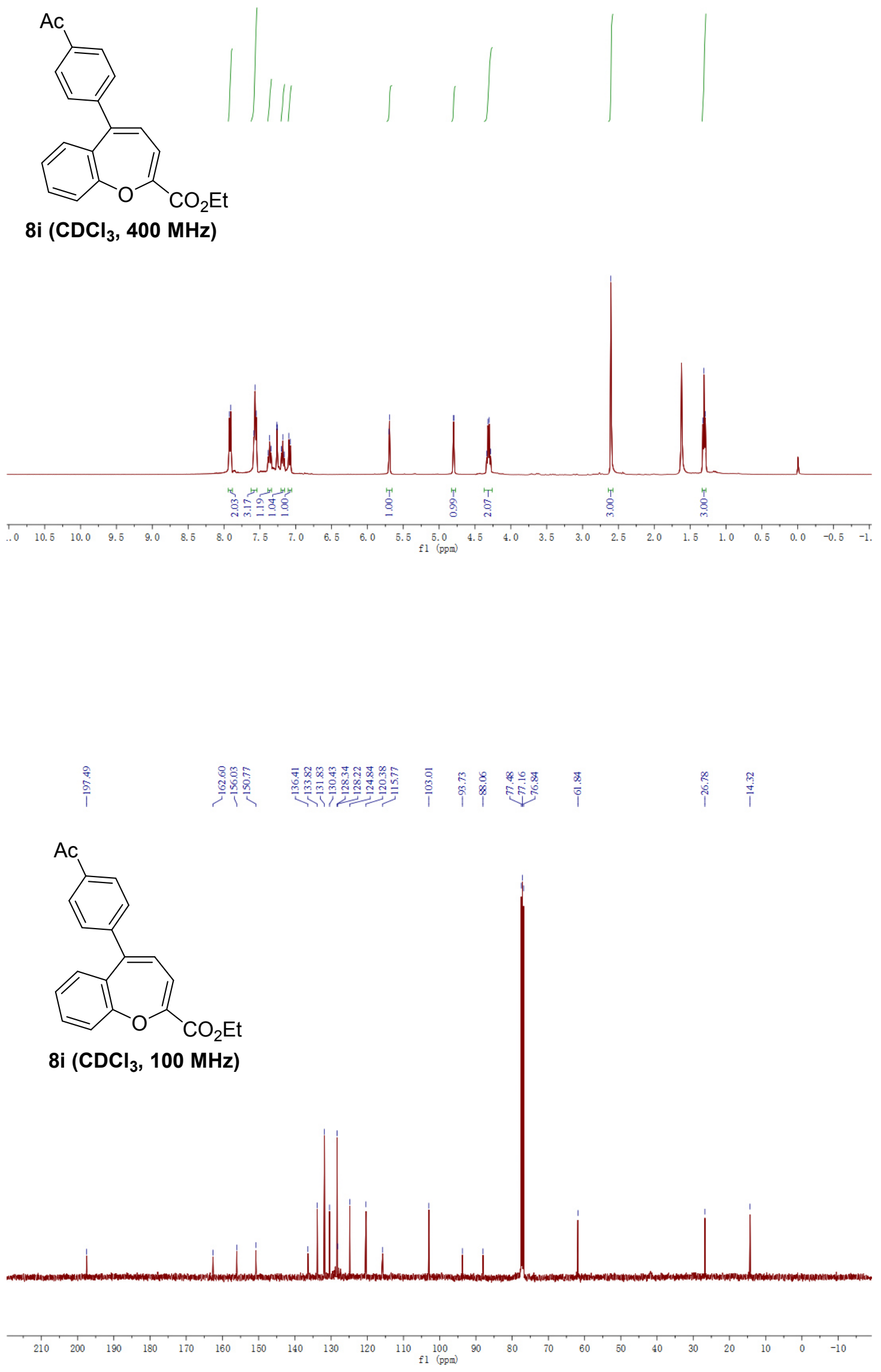

S16 

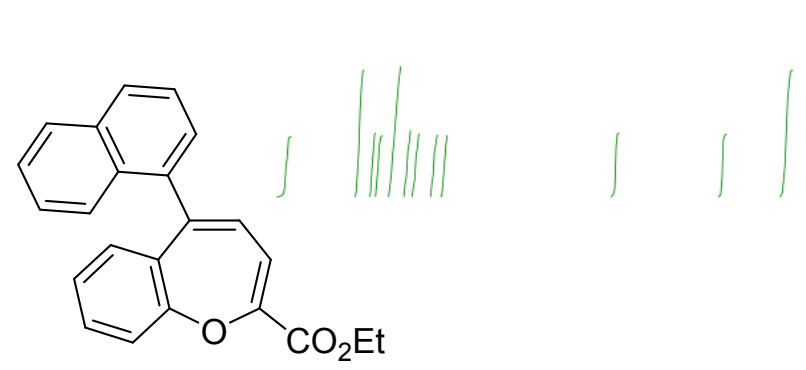

8j $\left(\mathrm{CDCl}_{3}, 400 \mathrm{MHz}\right)$
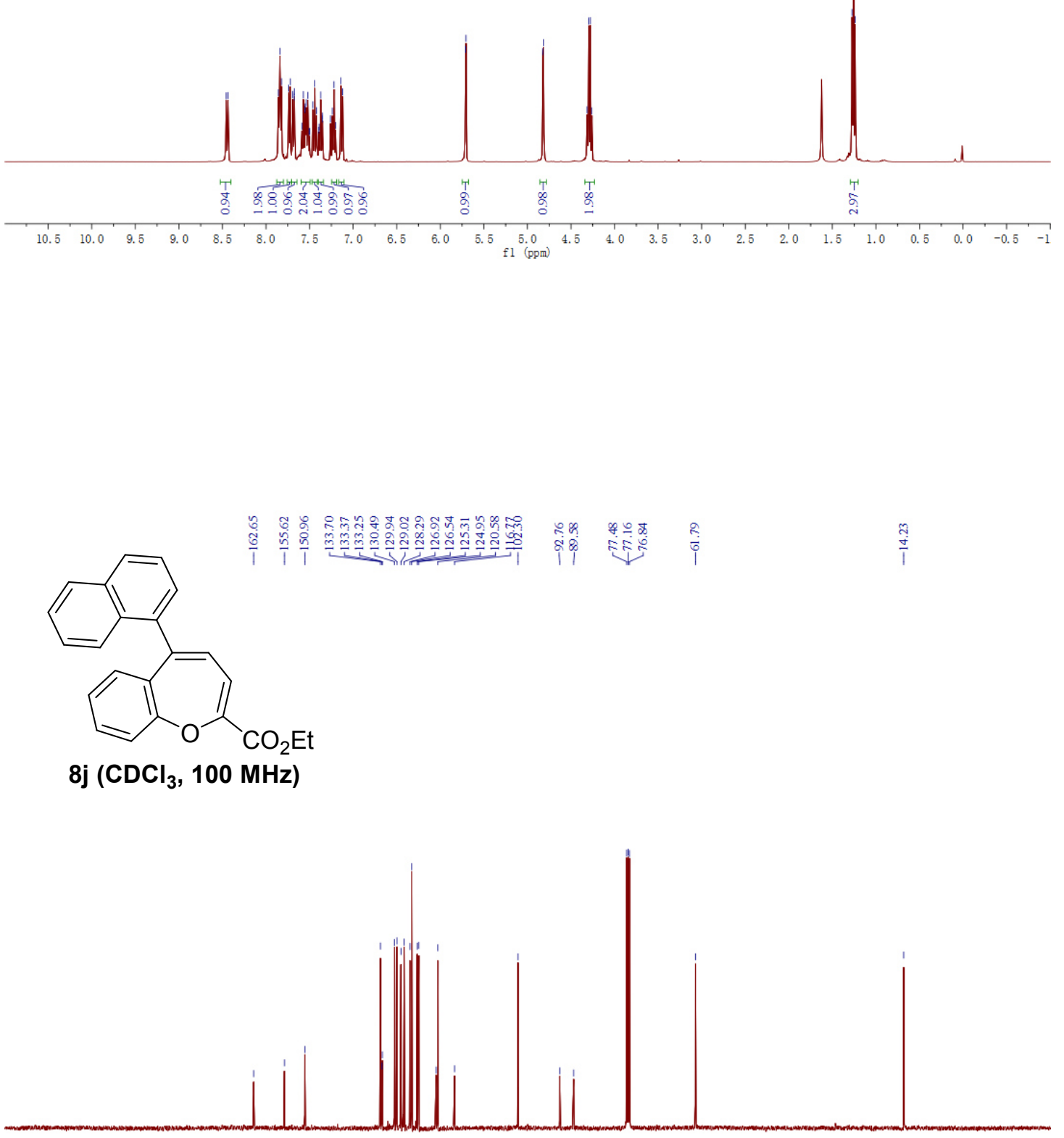

$\begin{array}{llllllllllll}210 & 200 & 190 & 180 & 170 & 160 & 150 & 140 & 130 & 120 & 110 & 100 \\ \mathrm{f} 1(\mathrm{ppm}) & 90\end{array}$ 


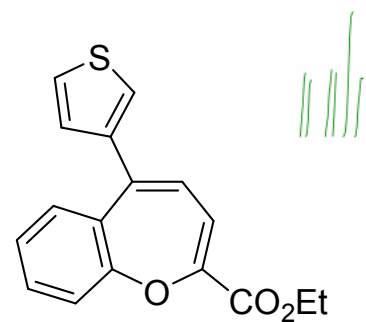

8k ( $\left.\mathrm{CDCl}_{3}, 400 \mathrm{MHz}\right)$
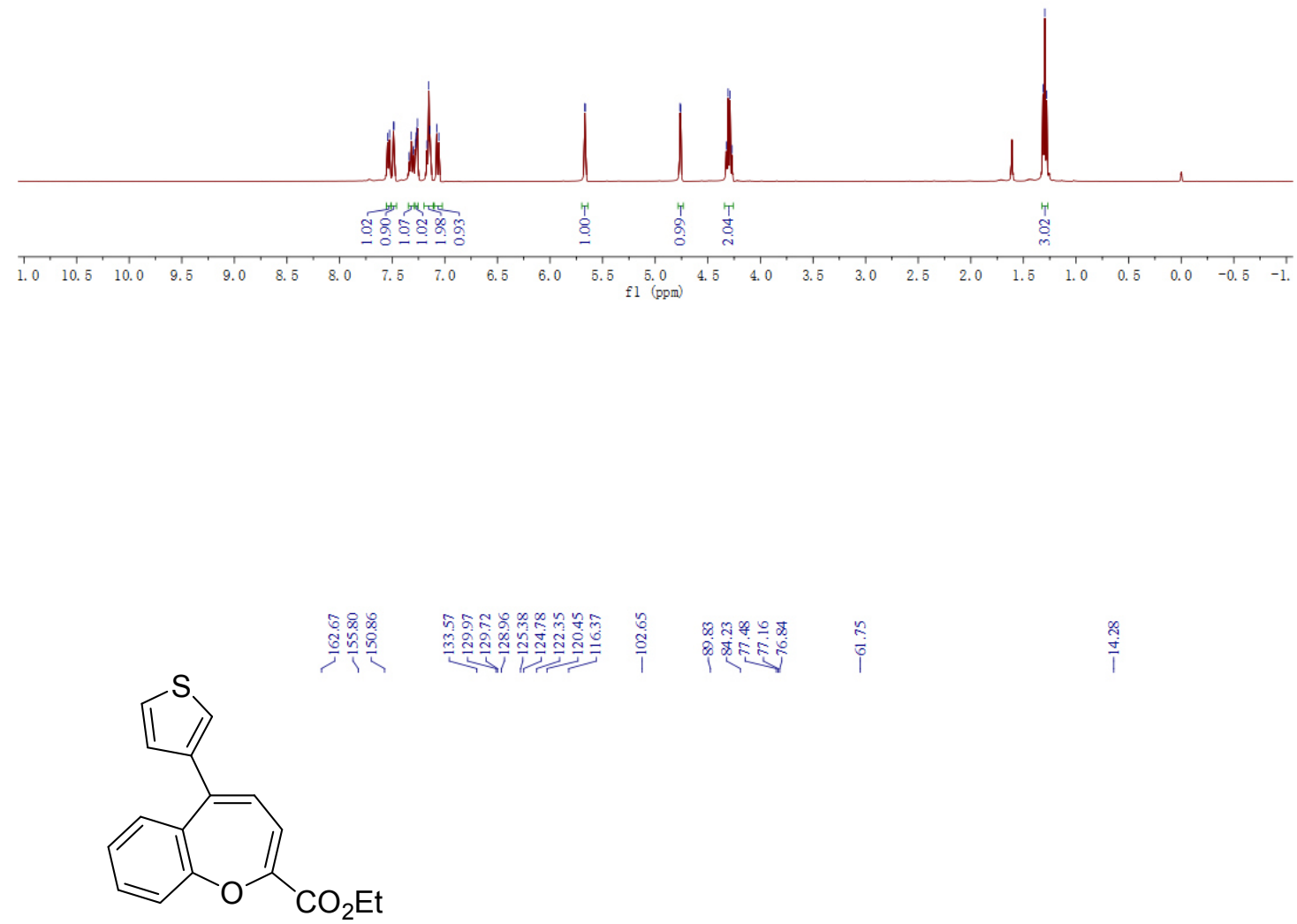

8k $\left(\mathrm{CDCl}_{3}, 100 \mathrm{MHz}\right)$

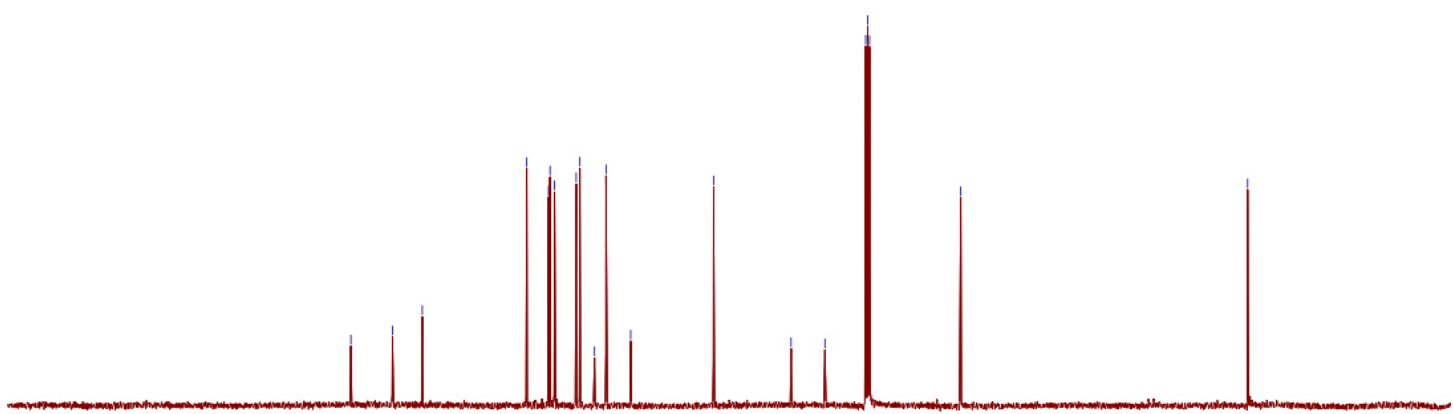

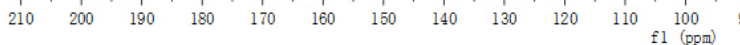




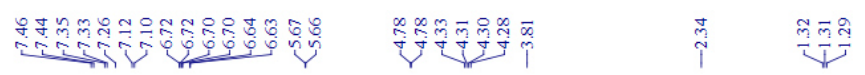<smiles>CCOC(=O)C1=CC=C(c2ccc(C)cc2)c2cc(OC)ccc2O1</smiles>

$8 \mathrm{l}\left(\mathrm{CDCl}_{3}, 400 \mathrm{MHz}\right)$
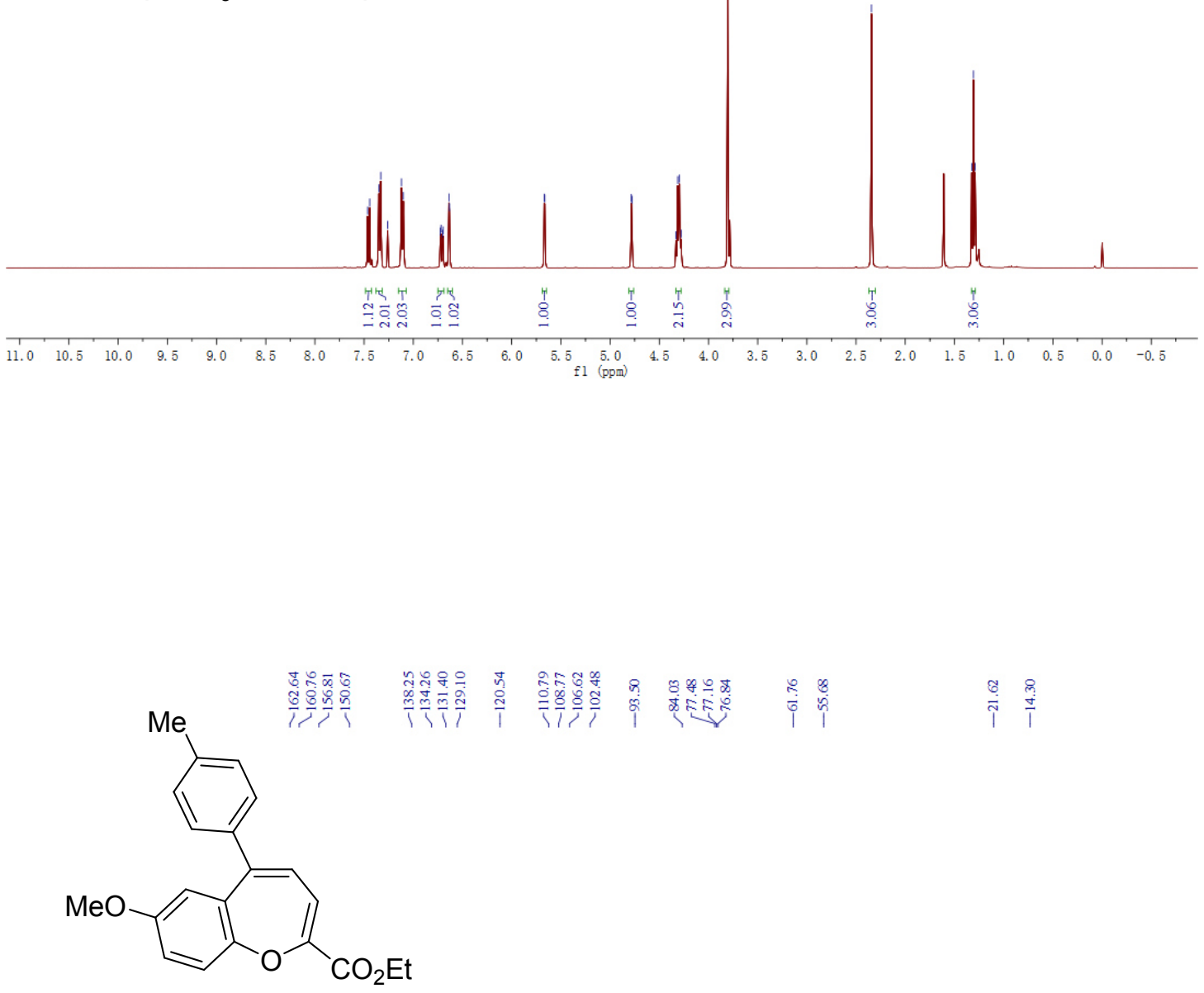

$8 \mathrm{l}\left(\mathrm{CDCl}_{3}, 100 \mathrm{MHz}\right)$

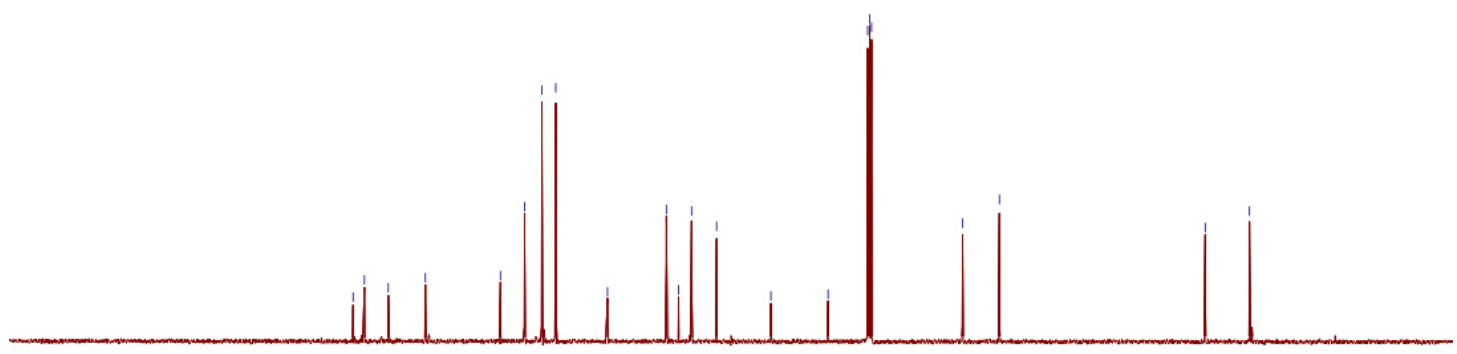

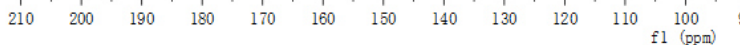



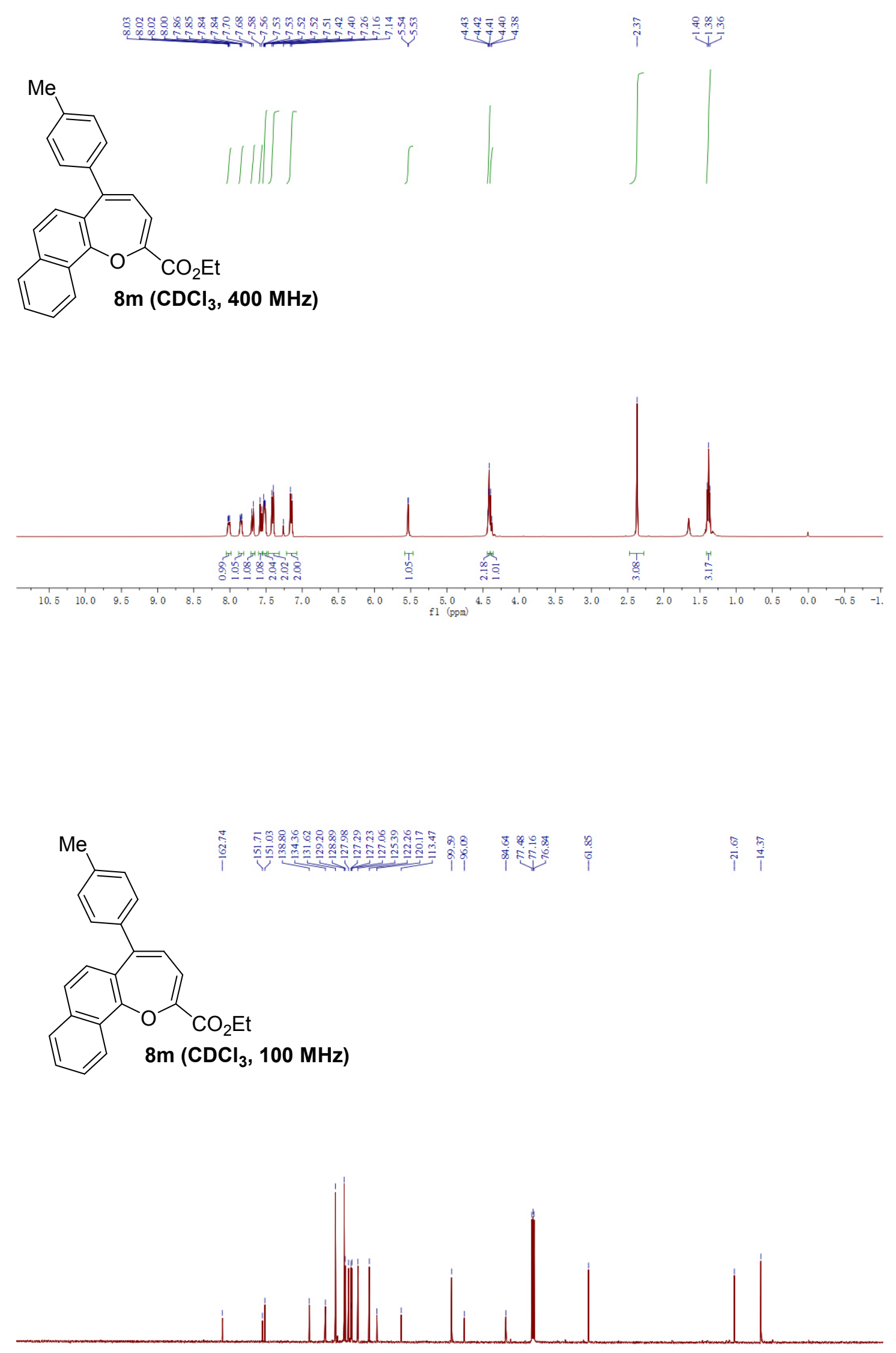

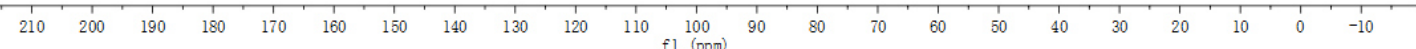




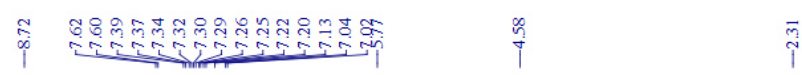

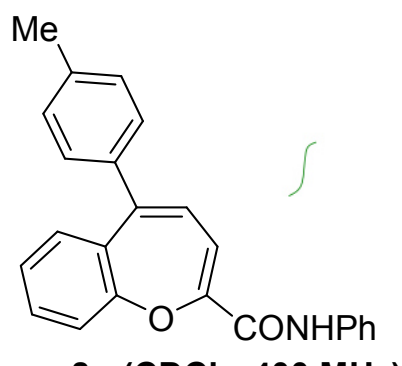

8n $\left(\mathrm{CDCl}_{3}, 400 \mathrm{MHz}\right)$
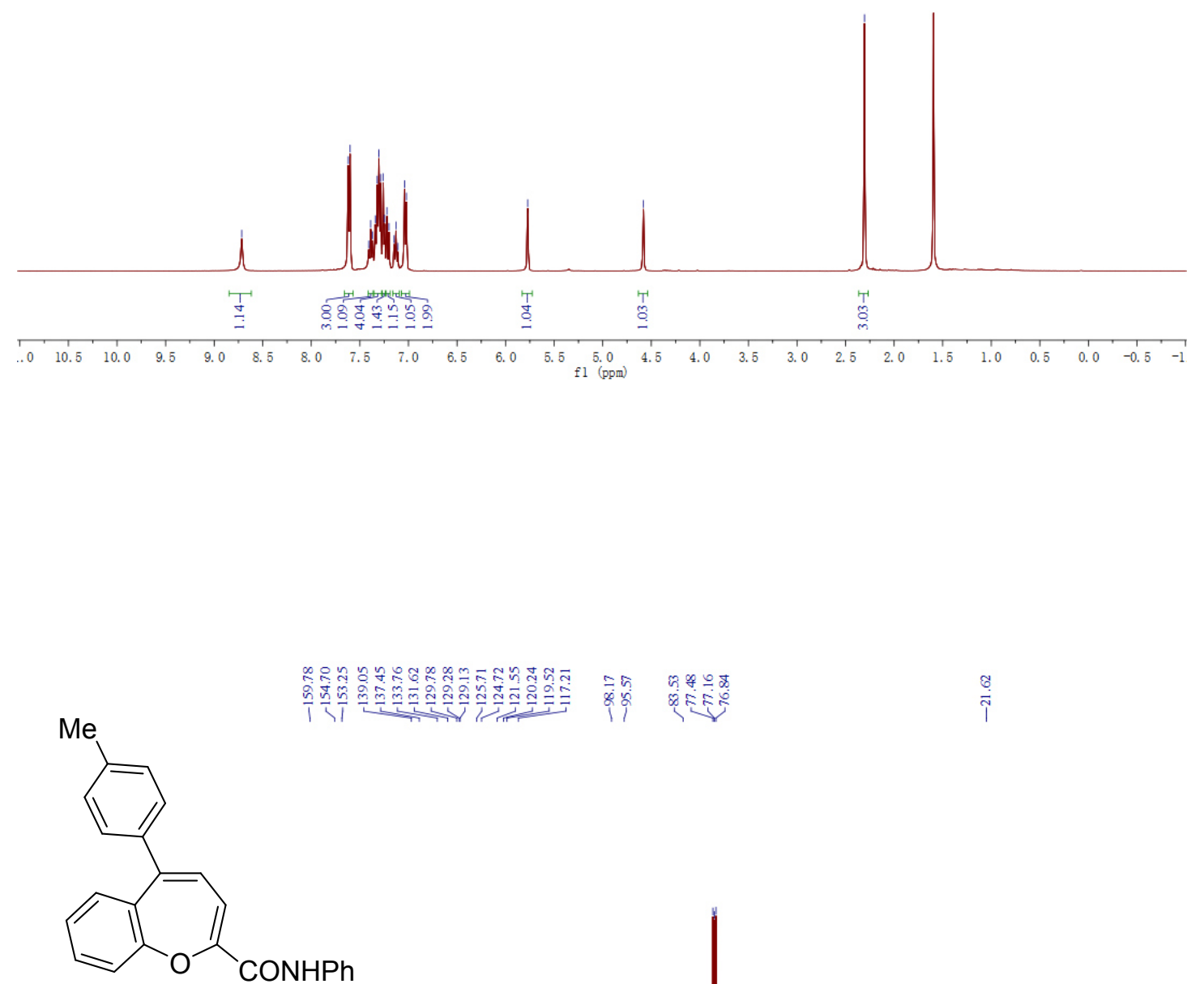

8n $\left(\mathrm{CDCl}_{3}, 100 \mathrm{MHz}\right)$

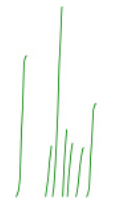



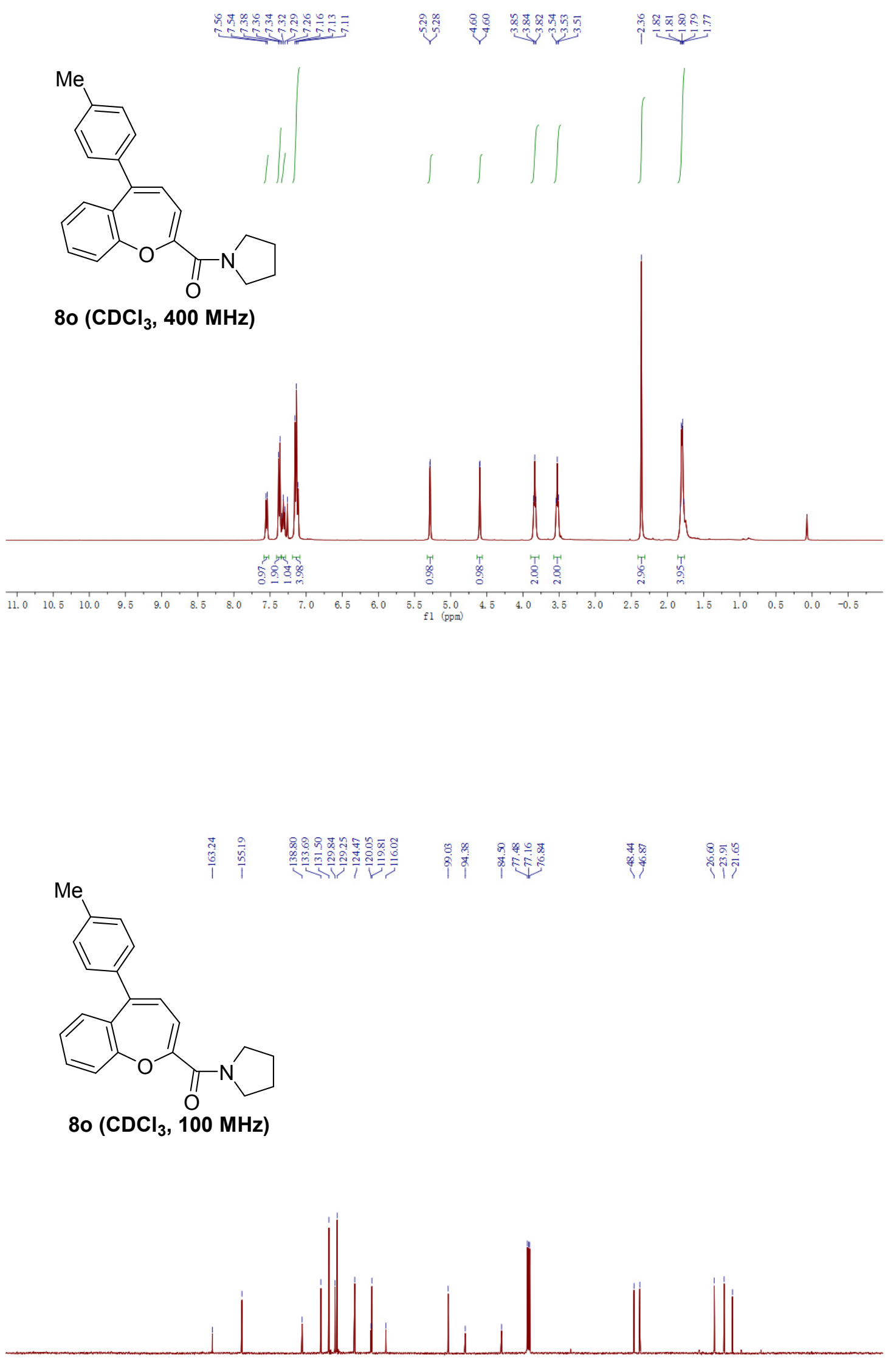

$\begin{array}{lllllllllll}210 & 200 & 190 & 180 & 170 & 160 & 150 & 140 & 130 & 120 & 110 \\ \mathrm{f} 1(\mathrm{ppm}) & 100\end{array}$ 


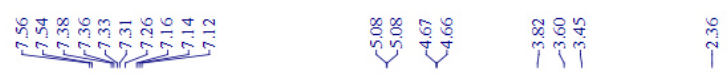
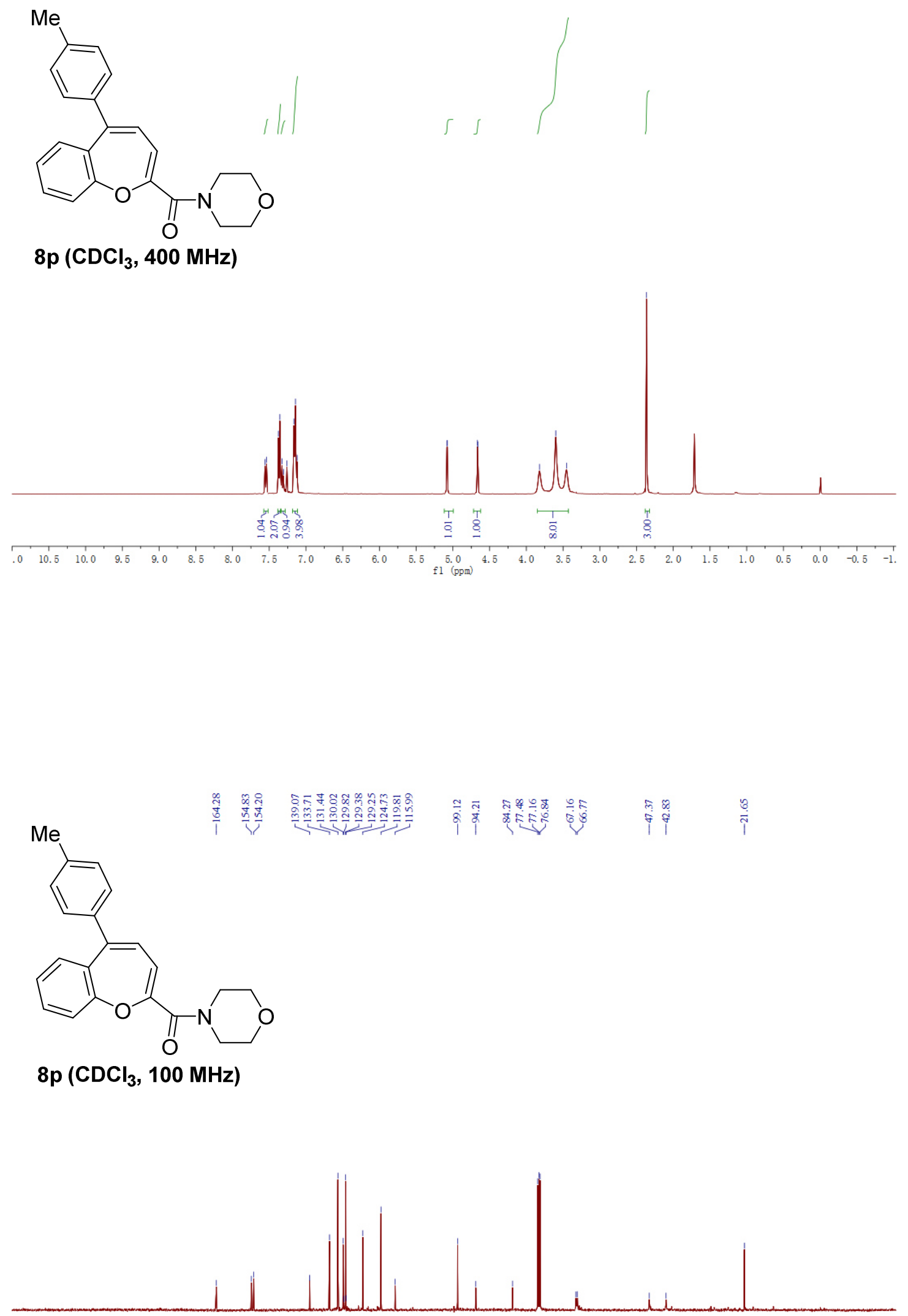

$\begin{array}{llllllllllll}210 & 200 & 190 & 180 & 170 & 160 & 150 & 140 & 130 & 120 & 110 & 100 \\ \mathrm{f} 1(\mathrm{ppm}) & 90\end{array}$ 